\title{
Race and IQ: A Theory-Based Review of the Research in Richard Nisbett's Intelligence and How to Get It
}

\author{
J. Philippe Rushton ${ }^{1, *}$ and Arthur R. Jensen ${ }^{2}$ \\ ${ }^{I}$ Department of Psychology, University of Western Ontario, London, Ontario, N6A 5C2, Canada \\ ${ }^{2}$ Department of Education, University of California, Berkeley, CA 94308
}

\begin{abstract}
We provide a detailed review of data from psychology, genetics, and neuroscience in a point-counterpoint format to enable readers to identify the merits and demerits of each side of the debate over whether the culture-only ( $0 \%$ genetic- $100 \%$ environmental) or nature + nurture model (50\% genetic-50\% environmental) best explains mean ethnic group differences in intelligence test scores: Jewish (mean IQ =113), East Asian (106), White (100), Hispanic (90), South Asian (87), African American (85), and sub-Saharan African (70). We juxtapose Richard Nisbett's position, expressed in his book Intelligence and How to Get It, with our own, to examine his thesis that cultural factors alone are sufficient to explain the differences and that the nature + nurture model we have presented over the last 40 years is unnecessary. We review the evidence in 14 topics of contention: (1) data to be explained; (2) malleability of IQ test scores; (3) cultureloaded versus $g$-loaded tests; (4) stereotype threat, caste, and "X" factors; (5) reaction-time measures; (6) within-race heritability; (7) between-race heritability; (8) sub-Saharan African IQ scores; (9) race differences in brain size; (10) sex differences in brain size; (11) trans-racial adoption studies; (12) racial admixture studies; (13) regression to the mean effects; and (14) human origins research and life-history traits. We conclude that the preponderance of evidence demonstrates that in intelligence, brain size, and other life history traits, East Asians average higher than do Europeans who average higher do South Asians, African Americans, or sub-Saharan Africans. The group differences are between 50 and $80 \%$ heritable.
\end{abstract}

Keywords: Flynn Effect, Jensen Effect, intelligence, IQ scores, heritability, g factor, race, genetics, IQ gap, educational interventions.

\section{THE DATA TO BE EXPLAINED}

Throughout the history of psychology, no question has been so persistent or so resistant to achieving consensus as that of the relative roles of nature and nurture in causing individual and group differences in cognitive ability $[1,2]$. The scientific debate goes back to the mid-19th century [3,4]. Starting with the widespread use of standardized mental tests in the U.S. during World War I (1917), average ethnic and racial group differences have been found. Especially vexing has been the cause(s) of the 15- to 18-point IQ difference (1.0 to 1.1 standard deviations, SDs) between Blacks and Whites. This remains a source of contention in the latest contribution to the debate, Nisbett's Intelligence and How to Get It [5].

The first major analysis of Black-White test scores began after World War I. The 23,596 Black draftees had an IQ of 83 (vs. 100 for Whites), with $13 \%$ of Blacks overlapping the White mean. Shuey [6] reported these and related data and reviewed 380 additional studies published over a 50-year period. She found the 15 point difference was consistent in student groups from preschool to college, as well as in members of the armed forces and specific groups such as delinquents, criminals, the gifted, and the developmentally challenged.

*Address correspondence to this author at the Department of Psychology, University of Western Ontario, London, Ontario, N6A 5C2, Canada;

Tel: 519-661-3685; E-mail: rushton@uwo.ca
In The Bell Curve, Herrnstein and Murray [7] described an original analysis of 11,878 youths (including 3,022 Blacks) from the 12-year National Longitudinal Survey of Youth. It found that most 17-year-olds with high scores on the Armed Forces Qualification Test, regardless of ethnic background, went on to occupational success by their late 20 s and early 30 s, while those with low scores were more inclined to welfare dependency. The study also showed that the average IQ for Jewish-Americans was higher than for East Asian-, White-, Latino-, and African-Americans (113, $106,103,89$, and 85, respectively, pp. 273-278).

We described the rival hereditarian and culture-only explanations of mean group IQ differences in our 60-page review, "Thirty Years of Research on Race Differences in Cognitive Ability" in the 2005 Psychology, Public Policy, and Law, a journal of the American Psychological Association [8]. The defining difference between the two explanations-an approximately $50 \%$ genetic- $50 \%$ environmental etiology for the nature + nurture hereditarian view versus an effectively $0 \%$ genetic- $100 \%$ environmental etiology for culture-only theory - is whether any significant part of the group differences is genetic. Intermediate positions (e.g., gene-environment interaction) can be operationally assigned to one or the other of the two positions depending on whether they accept a significant weighting for heritability. For example, if gene-environment interactions make it impossible to disentangle causality and apportion variance, then pragmatically that view is indistinguishable from the $100 \%$ 
culture-only program because it denies any numerical weight to the genetic component proposed by hereditarians.

Currently, the magnitude of the U.S. Black-White IQ difference is not in itself a major cause of scientific dispute. A recent meta-analytic review by Roth et al. [9] yielded a 1.1 SD difference (range $=0.38$ to 1.46 ) for a total of $6,246,729$ testees from corporate, military, and higher education samples. Further, that difference was consistent for college and university application tests such as the Scholastic Aptitude Test (SAT; $N=2.4$ million) and the Graduate Record Examination (GRE; $N=2.3$ million), as well as for tests of job applicants in corporate settings $(N=0.5$ million $)$ and in the military $(N=0.4$ million $)$.

The race-IQ debate was broadened considerably when research on East Asian Americans demonstrated they averaged a slightly higher IQ than White Americans [10]. The data base became truly international when Richard Lynn collated national IQ scores from 192 countries [11-14]. Going beyond the traditional three macro-races of Africans, Europeans, and East Asians, Lynn organized the data according to the ten "genetic clusters" (population groups) identified by Cavalli-Sforza et al. [15] in their 1994 History and Geography of Human Genes. Lynn tabulated 620 studies from the beginning of the twentieth century to the present $(N$ $=813,778$ ) and found the world average IQ to be 90 (Fig. 1). The East Asian cluster (Chinese, Japanese and Koreans) obtained the highest mean IQ at 105 , followed by Europeans (100), Inuit-Eskimos (91), South East Asians (87), Native American Indians (87), Pacific Islanders (85), South Asians \& North Africans (84), sub-Saharan Africans (67), Australian Aborigines (IQ 62), and Kalahari Bushmen \& Congo Pygmies (IQ 54).

In the developed world, IQ scores increased markedly from 1947 to 2002 - on average, about 3 points a decade over the last 50 years [16-18]. The mean went up by 18 points in the US alone. Since it was first observed, this secular increase, dubbed the "Flynn Effect" by Herrnstein and
Murray [7] after James R. Flynn who systematized the phenomenon and brought it to widespread attention, has been proffered as strong evidence that intelligence levels are substantially influenced by environmental factors (cf. Mingroni [19]). If such factors can change the mean IQ for the population as a whole, it is reasonable to suppose they could act so as to narrow the differences between Blacks and Whites.

Three new books, written from a cultural perspective, cite the secular gains as their main reason for believing the Black-White IQ gap must narrow: Richard Nisbett's 2009 Intelligence and How to Get It [5], James Flynn's 2007 What is Intelligence? [17], as well as Flynn's 2008 Where Have All the Liberals Gone? [18]. Of the three, Nisbett's book is the most comprehensive and builds upon the other two. In it, he renews his earlier critique of the nature + nurture position we have presented over the last 40 years [8, 20-23]. While Nisbett agrees with us that genes play a significant part in within group IQ differences, unlike us, he contends they play no significant part in between group differences. In a technical Appendix, "The Case for a Purely Environmental Basis for Black/White Differences in IQ," Nisbett submits nine categories of empirical evidence which he asserts refute our nature + nurture position, along with many of the conclusions of The Bell Curve [7].

In this paper we provide a point-counterpoint response to the evidence and arguments that Nisbett marshals against our nature + nurture model. In so doing, we use a format that should enable readers to identify the main topics of contention and the merits and demerits of each side of the debate. We discuss: the malleability of IQ scores; culture-loaded vs. g-loaded tests; stereotype threat, caste, and other " $\mathrm{X}$ " factors; reaction-time measures; within-race heritability; betweenrace heritability; sub-Saharan African IQ scores; race differences in brain size; sex differences in brain size; trans-racial adoption studies; racial admixture studies; regression to the mean effects; and human origins research and life-history theory.

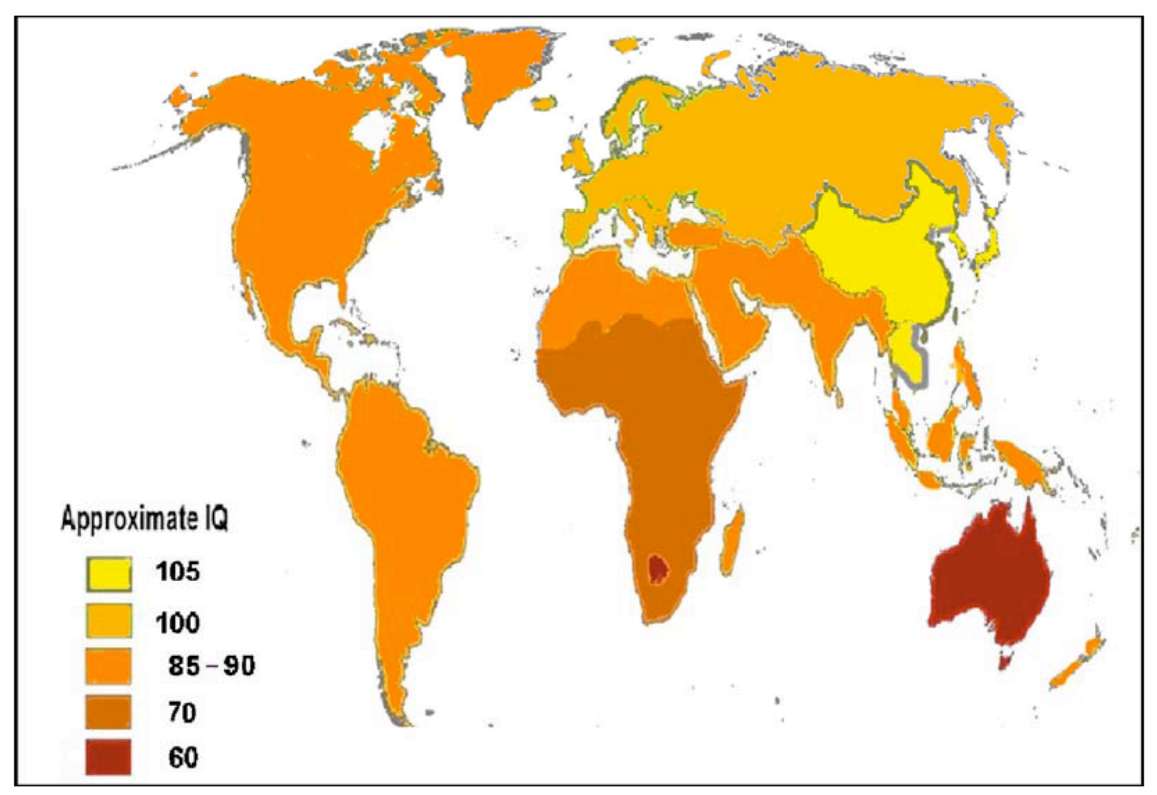

Fig. (1). World IQ Map of Indigenous Populations. 


\section{THE MALLEABILITY OF IQ SCORES}

Nisbett: James Flynn discovered that in the developed world as a whole, IQ scores increased markedly over the last 50 years. This suggests that the 15-point IQ difference between Blacks and Whites will gradually disappear over time. Indeed, Black IQ today is superior to White IQ in 1950!

Dickens and Flynn [24] showed the Black-White IQ gap narrowed by 5.5 points between 1972 and 2002. They documented a drop from 15 to 9.5 points on a combination of the Wechsler Intelligence Scale for Children (WISC), the Wechsler Adult Intelligence Scale (WAIS), the StanfordBinet, and the Armed Forces Qualification Test (AFQT). It is hard to overestimate the importance of a gap reduction of this magnitude. It reduces the ratio of Whites to Blacks with an IQ of 130 (the level needed to be a highly successful professional) from 18 to 1 to only 6 to 1 . Even including the several additional tests that Rushton and Jensen [25] said were wrongly omitted, the median Black IQ gain is still 4.5 points, which is not very different from the 5.5 point estimate given by Dickens and Flynn.

The Black-White difference shrank comparably on the National Assessment of Educational Progress (NAEP) LongTerm Trend tests. These have been given every few years since the early 1970 s by the U.S. Department of Education to a random sample of 9-, 13-, and 17-year-olds. For children born as early as 1954, the Black-White difference in reading and math averaged a full 1.2 SDs. For the most recent cohorts the gap is between .60 and .90 SDs - a very large reduction. It is interesting to note that if we convert the NAEP gains to IQ-type scales with a mean of 100 and SD of 15, and average the gains in math and reading across all age groups, we obtain a 5.4 point reduction in the Black-White education gap during the period for which Dickens and Flynn [24] found a 5.5 point reduction in the IQ gap.

Rushton and Jensen: In fact, there is very little evidence of any significant narrowing of the Black-White IQ gap. Rushton and Jensen [25] disputed Dickens and Flynn's [24] claim that Blacks gained 5.5 points by showing that Dickens and Flynn excluded several tests and then "projected" forward by multiplying a small gain from their highly select group of tests by more years than were available for most of the data. Dickens and Flynn excluded the Wonderlic Personnel Test, which showed a gain of only 2.4 points for Blacks between 1970 and 2001; the Kaufman Assessment Battery for Children (K-ABC), which showed a loss of 1 IQ point for Blacks between 1983 and 2004; the Woodcock-Johnson test, which showed a zero gain for Blacks; and the Differential Ability Scale, which showed a gain of only 1.83 points for Blacks between 1972 and 1986. Moreover, even the test data they did present did not directly support their conclusion. Simple arithmetic, rather than a multiplied projection, yielded a mean gain for Blacks of 3.4 points $(23 \%)$, not the 5.5 points claimed $(37 \%)$. Including the aforementioned tests reduced the gain from 3.4 to 2.1 points (14\%). Nisbett does not explain how he arrived at an overall Black gain of 4.5 IQ points (30\%) after including the four small (or negative) gain tests. Simple arithmetic applied to all eight tests yielded a mean gain for Blacks of only 2.1 points $(14 \%)$.

Other researchers have also failed to find a significant narrowing of the Black-White gap over the 30 years covered by Dickens and Flynn (i.e., from 1972 to 2002). For example, Murray [26, 27] concluded there was "no narrowing" in two independent studies. In the first, he found no narrowing in either verbal IQ or achievement test scores for children born to women in the 1979 sample of the National Longitudinal Survey of Youth. In the second, he found no narrowing for 6- to 65-year-olds in the Woodcock-Johnson standardizations of those born in the last half of the 1960s and early 1970s. When Roth et al. [9] confirmed the 1.1 SD difference in a sample of 6,246,729 corporate, military, and higher education testees, they also addressed the question of whether the differences were decreasing. They concluded that any reduction was "either small, potentially a function of sampling error...or nonexistent for highly g loaded instruments" $[9$, p. 323, our italics].

Nisbett seems also to have exaggerated a select sampling of NAEP scores to emphasize gains. Gottfredson [28, 29] found that from the 1970 s to the 1990 s, the Black-White difference on school achievement tests only narrowed from 1.07 to 0.89 SDs. Even this $20 \%$ reduction (not the $35 \%$ claimed by Nisbett) had: (a) occurred by the 1980s and no longer continued; and (b) was compatible with a heritability of $80 \%$ for IQ. However, the differences in results between Nisbett and Gottfredson are partly due to the NAEP scores coming in two distinct varieties. Nisbett reported on the NAEP Long Term Trend Assessment test, which measures student performance in Reading and Mathematics every four years or so and has remained relatively unchanged since its first administration. Gottfredson analyzed the Main NAEP Assessment test, which is given every two years and includes other subjects such as Science, Geography, and History, with test items modified every few years to reflect changing school curricula. In any case, when gains do occur, they may be due to increased familiarity with test material and "teaching the test" rather than to genuine improvement in learning (see Section 8.1).

\subsection{Is the African American Mean IQ Actually 78, not 85 ?}

When Murray [27] analyzed trends on the WoodcockJohnson test, he found that Black men born from 1925 to 1927 averaged 7.5 IQ points less than those born in later years. This was because Blacks born in the earliest years averaged 1.59 SDs below Whites rather than only the more typical 1 SD. Black IQs increased from 78 to the more typical 85 in later standardizations.

Murray's results suggested the hypothesis that the BlackWhite IQ gap in the US is actually 22 points, not 15 , a possibility supported by data from World War II military samples. The Black-White difference on the Army General Classification Test (AGCT) for 1944-1945 inductions was 1.52 SDs [2]. As Murray noted, the military testing during World War II was probably the most representative sampling of African American IQ ever undertaken. It was more inclusive than that conducted during World War I, which had excluded most of the $70 \%$ of African Americans who still lived in the rural South and were unschooled or very poorly schooled. This segment of the overall U.S. Black population, which had a lower mean IQ, was also underrepresented in the studies collated and analyzed by Shuey [6]. 
An IQ of 71 was found for the Black children in an entire school district from a rural county in Georgia in the U. S. Deep South; the White IQ in the same county was 101 [30]. Compatible with this finding are the results from Hills and Stanley [31] who gave the School and College Ability Test (SCAT), a deliberately easier test than the more usually administered Scholastic Aptitude Test (SAT), to all-Black college students in Georgia. They found that the scores were normally distributed and predicted college grades. However, the average for the Black college students on the SCAT was at about the 50th percentile on 8th grade national norms. Even today, test developers and educational researchers seldom get to examine the very lowest scoring segments of the Black population in inner cities.

\section{CULTURE-LOADED VERSUS HERITABLE $g$-LOADED TESTS}

Nisbett: Herrnstein and Murray [7] and Rushton and Jensen [8] argue that because Blacks and Whites differ more on those IQ items with higher $g$ loadings (correlations with $g$, the general factor of mental ability), this constitutes evidence for the biological and genetic nature of the BlackWhite difference. However, many social scientists say that $g$ is little more than a statistical necessity and is of limited interest. In any case, Dickens and Flynn [24] showed that Blacks gained almost as much (5.13 points) on $g$-weighted tests as on non- $g$-weighted tests.

My own (Nisbett) view is that when it comes to race differences, the $g$ factor is a red herring. This is because (a) Flynn [32] showed the secular trends occur on $g$ loaded tests, and (b) the secular trends are without doubt almost entirely environmental in origin. This produces an absurdity since Rushton and Jensen allege that $g$ loaded tests are more genetically influenced! Rushton and Jensen [8] made a related claim that Blacks do worse on subtests with larger amounts of inbreeding depression (the lowering of an IQ score in offspring who receive the same harmful recessive genes from each of their closely related parents). On the face of it, if those subtests that suffer the most from inbreeding depression are the ones that show the greatest difference between Blacks and Whites, this would indicate evidence for the race difference being genetic. However, Flynn [32] found inbreeding depression scores correlate almost as highly with the secular gains as they do with Black-White differences. Thus, we are confronted with another absurdity. If we believe that inbreeding depression is an indicator of the genetic nature of Black-White differences, we would also have to believe that the secular rise in IQ has a genetic cause.

Rushton \& Jensen: That Black-White IQ differences are more pronounced on the more $g$ loaded and more heritable components of tests does indeed imply the differences are partly genetic in origin. However, it is a false claim that $g$ and inbreeding depression correlate with the secular rise in IQ. We review the tortured history of this claim and in the process find we have eliminated the Flynn Effect as a reason to expect any narrowing of the Black-White differences.

The story begins with a 1972 study by Nichols [33] who found a .67 correlation between 13 IQ test heritabilities and the magnitude of Black-White differences on the same tests. In 1973, Jensen [21] calculated environmentalities (defined as the degree to which sibling correlations departed from the pure genetic expectation of .50) for 16 tests and found they were inversely related to Black-White differences on the same tests $(r=-.70)$. In 1989, Rushton [34] correlated inbreeding depression effects for 11 subtests of the Wechsler Intelligence Scale for Children (WISC) with Black-White differences on the same tests in the US $(r=.48 ; P<.05)$. Inbreeding depression, a purely genetic effect, occurs when offspring receive two copies of the same harmful recessive gene from each of their closely related parents. The inbreeding depression effects had been calculated by Schull and Neel [35] from 1,854 cousin marriages in Japan and showed a 5 point decrement (.33 SD) in the offspring. There is no explanation other than a genetic one for inbreeding depression.

With respect to the $g$ factor, Jensen [22, pp. 369-379] summarized 17 independent data sets of nearly 45,000 Blacks and 245,000 Whites derived from 149 psychometric tests and found the $g$ loadings of the subtests consistently predicted the magnitude of the Black-White differences $(r=$ $.62, P<.05)$. This was true even among 3 -year-olds administered 8 subtests of the Stanford-Binet; the rank-order correlation between the $g$ loadings and the Black-White differences being .71 $(P<.05)$ [36]. In Hawaii, IQ differences between East Asians and Whites (favoring East Asians) were greater on the more $g$ loaded of 15 subtests among people of Japanese, Chinese, and European ancestry [37]. In Zimbabwe, Rushton \& Jensen [38] found $77 \%$ of the difference between Africans and Whites was due to $g$ in a principal factor reanalysis of WISC-R data from 12- to 14-year-olds originally published by Zindi [39]. In South Africa, Rushton et al. [40, 41] found the differences between Black, South Asian, and White engineering students were greater on the more $g$ loaded items from the Progressive Matrices.

In Fig. (2), Rushton [23, p. 188] juxtaposed the results on $g$, inbreeding depression, and Black-White differences to support his theory of the genetic origin of the race differences. It was to counter Rushton's conclusion and the data in Fig. (2) that Flynn [42] began a series of exchanges with Rushton. In the first [42], he found correlations ranging from -.08 to +.18 (mean .08; all non-significant) between the inbreeding depression scores and 5 sets of secular gains on the same 11 WISC subtests. Then, he correlated the inbreeding depression scores with the 6 Performance subtests, but these results were also non-significant (mean $r=-.05$ ). However, when Flynn looked at the 5 Verbal subtests, he found a correlation of .52. Although this was not significant either, its numerical value, and the fact that a correlation of .30 or higher was found for all 5 Verbal scales in all 5 samples, allowed Flynn to publish "Evidence against Rushton" (p. 373).

In response, Rushton [43] provided a more complete analysis. Table 1 presents the correlations for all the data presented by Rushton [23] and Flynn [42]. The zero-order correlations are in the top half of the matrix and the firstorder partial correlations (after controlling for reliability) are in the lower half of the matrix. As can be seen, inbreeding depression correlated positively with the Black-White differences $(r=.48 ; P<.05)$ and also with the $g$ loadings from the WISC-R and WISC-III $(.61, .39)$ but not with the five sets of gain scores (mean $r=.13$; range $=-.07$ to .29 ). The two sets of $g$ loadings correlated significantly positive with the Black- 

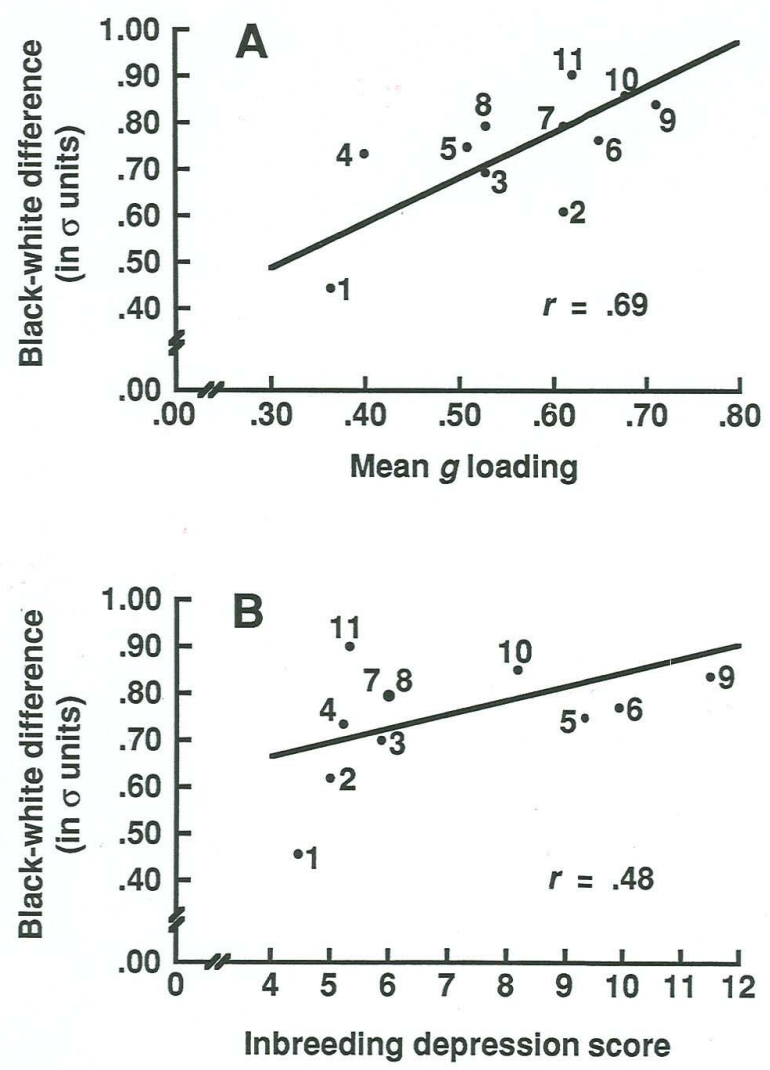

Fig. (2). Regression of Black-White differences on g loadings (Panel A) and on inbreeding depression scores (Panel B). The numbers indicate subtests from the Wechsler Intelligence Scale for Children-Revised: 1, Coding; 2, Arithmetic; 3, Picture completion; 4, Mazes; 5, Picture arrangement; 6, Similarities; 7, Comprehension; 8, Object assembly; 9, Vocabulary; 10, Information; 11, Block design. (From Rushton [23], p. 188, Figure 9.1).

White differences $(.53, .69)$ but significantly negative with the 10 sets of $g$ loadings (mean $r=-.33$; range from -.04 to $.73 ; P<.00001$; Fisher [44], pp. 99-101).

Rushton [43] also carried out a principal components analysis on the partialed correlation matrix in Table $\mathbf{1}$ and extracted two significant components with eigenvalues $>1$. These are presented in both unrotated and varimax rotated forms in Table 2. The relevant findings are: (1) the IQ gains on the WISC-R and WISC-III form a cluster, showing that the secular trend in overall test scores is a reliable phenomenon; but (2) this cluster is independent of a second cluster formed by Black-White differences, inbreeding depression scores (a purely genetic effect), and $g$ factor-loadings (a largely genetic effect). The analyses were repeated in alternate ways and the results found to be very similar.

Flynn [45] replied again, and then again [17, 18, 32], to provide a "counterweight to Rushton's analysis" [32, p. 214]. For example, in collaboration with William Dickens, Flynn [32] produced a drastically revised set of analyses, one of which purported to show that $g$ and inbreeding depression correlated with the secular trends (as cited by Nisbett). Flynn: (a) discarded the WISC Maze subtest, thereby reducing the number of WISC subtests from 11 to 10 (no reason given); (b) discarded the gain scores and Black-White differ- ences on the WISC-III on the grounds that most of the data were on the WISC-R; (c) averaged the five sets of gain scores on the grounds that five gain indicators were too many for Rushton's factor analysis to be fair (though there was an equal number of variables for $g$ ); and (d) calculated a new $g$ loading for the Wechsler subtests by examining some of their correlations with the Raven's Progressive Matrices (those "retained" from a broader sampling). Flynn argued that it was necessary to calculate a revised $g$ this way because the Matrices, an excellent measure of "fluid" $g$, showed the greatest secular gains and Rushton had measured "crystallized" $g$ (though Rushton had used the standard method for extracting $g$ from the Wechsler tests, and Flynn's new $g$ correlated not at all with the WISC $g$ ).

Using this truncated set of new variables (with old labels), Flynn [32] now reported a quite different set of correlations than had Rushton [43]. Although none of Flynn's new correlations were significant with $N=10$ : .50 between $g$ and secular gains (reversing Rushton's highly significant finding of -.33); .28 between inbreeding depression and secular gains (up from Rushton's in effect zero .13); .50 between $g$ and Black-White differences (down from Rushton's significant correlation of .61); and. 29 between inbreeding depression and Black-White differences (down from Rush- 
Table 1. Pearson Correlations of the Wechsler Intelligence Scale for Children-Revised (Zero-Order Correlations Above Diagonal; Reliabilities Partialed Out Below Diagonal)

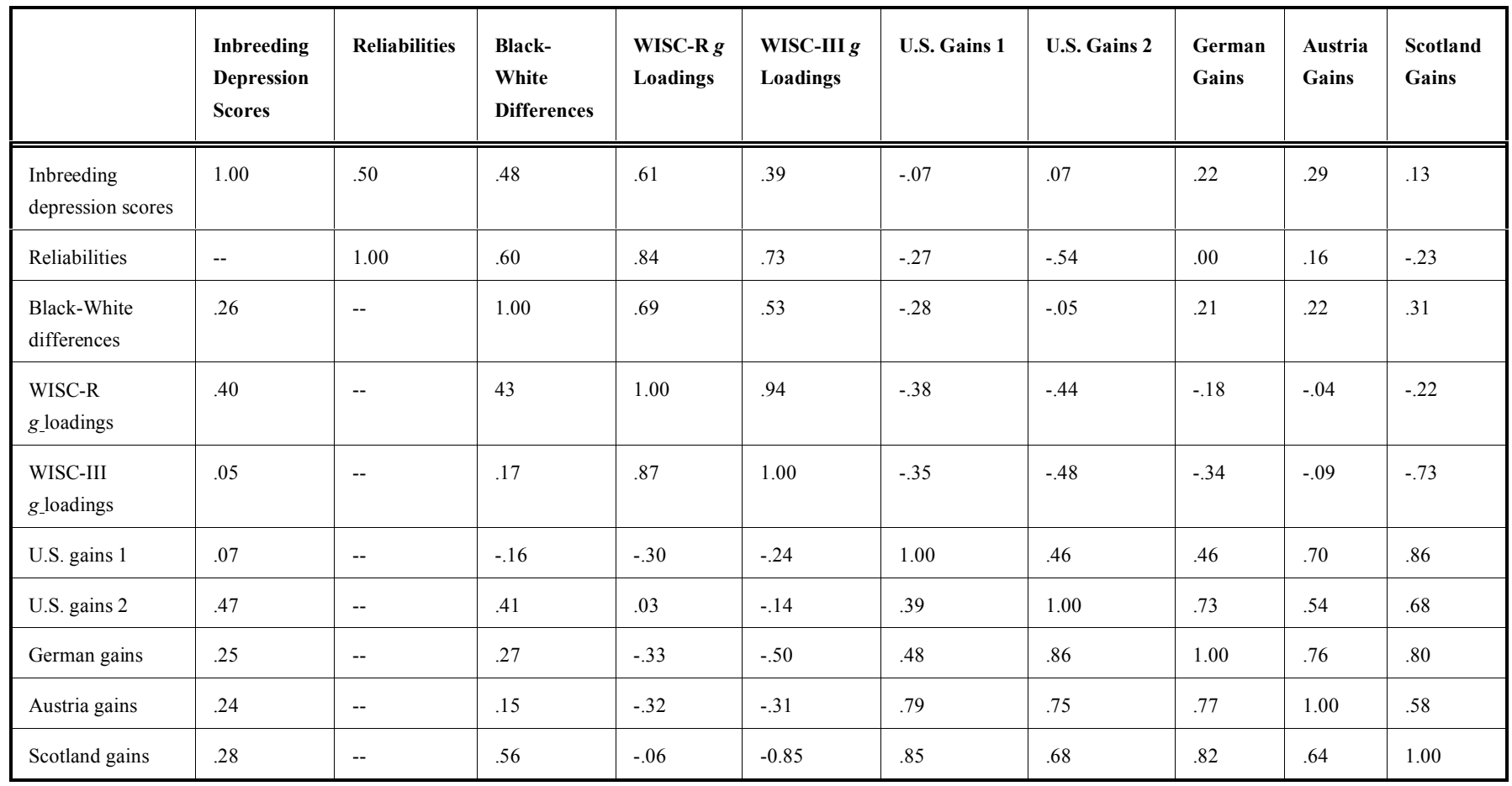

Note: From Rushton [43].

Table 2. Principal Components Analysis and Varimax Rotation for Pearson Correlations of Inbreeding Depression Scores, BlackWhite Differences, $g$ Loadings, and Gains Over Time on the Wechsler Intelligence Scales for Children With Reliability Partialed Out

\begin{tabular}{|c|c|c|c|c|}
\hline \multicolumn{5}{|c|}{ Principal Components } \\
\hline Variables & \multicolumn{2}{|c|}{ Unrotated Loadings } & \multicolumn{2}{|c|}{ Varimax Rotated Loadings } \\
\hline Inbreeding depression scores from Japan (WISC-R) & .31 & .61 & .26 & .63 \\
\hline Black-White differences from the U.S. (WISC-R) & .29 & .70 & .23 & .72 \\
\hline WISC-III g loadings from the U.S. & -.61 & .64 & -.66 & .59 \\
\hline U.S. gains 1 (WISC to WISC-R) & .73 & -.20 & .75 & -.13 \\
\hline U.S. gains 2 (WISC-R to WISC-III) & .81 & .40 & .77 & .47 \\
\hline$\%$ of total variance explained & 48.6 & 25.49 & 48.44 & 25.65 \\
\hline
\end{tabular}

Note. From Rushton [43].

ton's significant correlation of .43). Flynn acknowledged that, "The data contained herein are not robust" [32, p. 212].

In our opinion, it was highly misleading of Nisbett [5] to assert that the relation between $g$ and Black-White differences is a "red herring" due to $g$ correlating with the secular trends. Nisbett withheld from his readers Rushton's [43] finding that $g$ correlated significantly negatively with 10 sets of secular gains $(r=-.33 ; P<.0001)$; that inbreeding depression correlated with Black-White differences $(r=.48 ; P<$. $05)$; and that Flynn's re-constituted correlation between inbreeding depression and secular gains $(r=.29)$ was not sig- 
nificant. Moreover, when Nisbett favorably cited Flynn's [18] most recent book, he neglected to mention that Flynn had apparently changed his mind about the relation between $g$ and the Black-White gains. While Flynn still maintains that the race differences are mostly environmental in origin, he now agrees with Rushton and Jensen [8] and disagrees with Nisbett [5], as well as his own former opinion [32]:

There are two messages. The first is familiar: You cannot dismiss black gains on whites just because they do not tally with the $g$ loadings of subtests. But the second is new and unexpected. The brute fact that black gains on whites do not tally with $g$ loadings tells us something about causes. The causes of the black gains are like hearing aids. They do cut the cognitive gap but they are not eliminating the root causes. And conversely, if the root causes are somehow eliminated, we can be confident that the IQ gap and the $g$ gap will both disappear (p. 85).

Rushton's [43] finding that the Flynn Effect is not on $g$ has been corroborated by several independent researchers (though some early studies promised otherwise [e.g., 22, 46, 47, 48]. For example, Must et al. [49] found a negative correlation $(r=-.40)$ between $g$ and gain scores over a 60-year period on 12 subtests of the Estonian National Intelligence Test. In the Netherlands, te Nijenhuis and van der Flier [50] found a modest negative correlation between $g$ and gains on two IQ tests. Most recently a meta-analysis of 17 studies $(N=12,732)$ by te Nijenhuis and van der Flier [51] corroborated Rushton's [43] finding of an overall negative correlation (rho $=-.33 ; P<.0001$ ) between $g$ and the secular gains.

Further evidence that the secular gains are qualitatively different from Black-White differences comes from studies using multi-group confirmatory factor analysis (MGCFA) to examine measurement invariance in both types of scores (Wicherts et al. [52]). Five independent data sets showed rising IQ scores, but also an absence of measurement invariance, thereby indicating that the test scores had different meanings for the different cohorts. By contrast, when BlackWhite IQ differences were examined from Dolan [53] and Dolan and Hamaker [54], measurement invariance was found, indicating the test scores had the same meaning. These results suggest that cohort gaps in IQ tell us nothing about population group differences (Wicherts et al. [52]).

\subsection{Spearman's Hypothesis and Jensen Effects}

In 1904, Charles Spearman [55] introduced the term $g$ to represent the general factor of intelligence, that is, the underlying process common to all mental tests. He conjectured that Black-White differences would be "most marked in just those [tests] which are known to be saturated with $g$ " (p. 379). Jensen [56] dubbed this "Spearman's hypothesis" (p. 535) and carried out several studies to test it. Osborne [57] renamed it the "Spearman-Jensen hypothesis" because it was Jensen who brought Spearman's hypothesis to widespread attention and did the empirical work confirming it. Rushton [58] then proposed the term "Jensen Effect" be used whenever a significant correlation occurred between $g$-factor loadings and any other variable. Jensen Effects are not omnipresent and their absence can be as informative as their presence.
For example, the Flynn Effect (the secular rise in IQ) is not a Jensen Effect because it does not occur on $g$.

Jensen [22] documented that $g$ is the "active ingredient" of IQ scores, and is embedded to a greater or lesser extent in every question on an intelligence test. He showed that a test's $g$ loading is the best predictor, not just of that test's correlation with scholastic and work-place performance, but of biological measures such as heritability coefficients determined from twin studies, inbreeding depression scores calculated in children of cousin-marriages, brain evoked potentials, brain $\mathrm{pH}$ levels, brain glucose metabolism, as well as nerve conduction velocity and reaction time measures. These correlations argue strongly for the heritable and biological, as opposed to the mere statistical reality of $g$.

\subsection{The Method of Correlated Vectors}

As summarized above, studies have found Black-White IQ differences are greater on the more $g$ loaded and more heritable of IQ sub-tests, implying the group differences are genetic in origin. Many of these studies used the method of correlated vectors, a procedure developed by Jensen [22] to determine whether there is an association between a column of quantified elements (such as a test's $g$ loadings) and any parallel column of independently derived scores (such as mean differences between groups). Criticisms have been made of the above methodology. For example, Dolan et al [59] and Ashton and Lee [60] argue that the method of correlated vectors (MCV) lacks specificity so that Jensen Effects might occur even when differences are not on $g$, and so more powerful statistics are needed, such as multi-group confirmatory factor analysis (MGCFA). However, this criticism misses the point because there is no absolute claim that the $g$ effects have been proven, only that what is observed is what would have been expected if an underlying $g$ did in fact exist (see Bartholomew [61] for the logic of $g$ inferences). Thus, the onus is on the critics of $g$ to identify whether some other factor is operating. In any case, several studies have corroborated the results on $g$ and group differences using MGCFA with White-Black differences in the US [52], White-Black differences in South Africa [41], and White-Roma differences in Serbia [62] (the Roma, or Gypsies, are a people of South Asian origin). These latter two results also address a related criticism sometimes made, that the Raven's tests have not been shown to have a high $g$ loading among groups such as the Roma or Africans.

Most recently, Rushton et al. [63] used the method of correlated vectors to correlate item heritabilities for each of the diagrammatic puzzles of the Raven's Colored and Standard Progressive Matrices (CPM/SPM) with group differences in pass rates on the same puzzles. In Study 1, 199 pairs of 5- to 7-year-old monozygotic (MZ) and dizygotic (DZ) twins reared together provided heritabilities for 36 puzzles from the CPM. These correlated with the differences in pass rates between the twins and 94 Roma (Gypsies) living in Serbia $(r=.32 ; P<.05)$. In Study 2, 152 pairs of adult MZ and DZ twins from the Minnesota Study of Twins Reared Apart provided heritabilities for 58 puzzles from the SPM. These correlated with the differences in pass rates calculated for 11 diverse samples, including the Roma in Serbia, and Asian, White, Colored, and Black students in South Africa (overall mean $r=.40 ; P<.05$ ). 
Rushton et al.'s [63] study was criticized by Wicherts and Johnson [64] who argued the results were due to statistical artifacts because all the analyses had been carried out on dichotomous items and these were too imprecise to generalize across samples. Wicherts and Johnson showed that the effective range of each item to discriminate true ability differences was fairly narrow, and its place in the distribution depended on whether individuals with high or low ability were responding. Although Rushton et al. controlled for measurement reliability and for the variance in item pass rates and found the heritabilities still correlated with group differences, Wicherts and Johnson deemed the controls inadequate. They carried out several computer simulations to support their position.

In our view, the problems raised by Wicherts and Johnson [64] are beside the point because the empirical literature shows there is, in fact, remarkable generalizability for both item characteristics and heritability estimates. For example, items found relatively difficult (or easy) for twins in North America are the ones found relatively difficult (or easy) by the Roma in Serbia and by the Whites, Asians, Coloreds, and Blacks in South Africa (mean $r=.87$ ). Moreover, as described above, Rushton [34] found inbreeding depression effects on 11 WISC subtests calculated from cousin marriages in Japan correlated with the magnitude of BlackWhite differences in America!

Nonetheless, to examine the substance of the Wicherts and Johnson [64] critique, we re-analyzed Rushton et al.'s [63] data. To circumvent the difficulties claimed to operate at the item level, we organized the items into parcels, going from low to high heritability, which we then related to the group differences in pass rates on the same parcels. Aggregating items is a standard procedure in psychometrics because, according to classical test theory, aggregation causes "error variance" and "specificity variance" to average out, while "true score variance" accumulates. Fig. (3A) plots 6 parcels of 6 heritabilities against 6 sets of pass rate differences between the twins and the Serbian Roma based on the 36 item heritabilities from Rushton et al.'s Study 1. Fig. (3B) plots 6 parcels of 9 heritabilities against 6 sets of pass rate differences for the White, Asian, Colored, and Black high school students in South Africa using the 58 item heritabilities from Rushton et al.'s Study 2. In Fig. (3B), parcel 1 contains the lowest heritabilities (plus two extra items), and parcel 6 the highest (plus two extra items). Despite an $N$ of only 6 , the correlations between the parcels of heritabilities and the pass rates were highly significant. For the data in Fig. (3A), $r=.47(P<.01)$ and for that in Fig. (3B), the mean $r=.74$ (range $=.55$ to $.93 ; P<.00001$; Fisher, [44], pp. 99-101). These results provide additional support for the nature + nurture hypothesis that the cause of group differences is the same as the cause of individual differences, about $50 \%$ genetic and $50 \%$ environmental [22].

\section{STEREOTYPE THREAT, CASTE, AND OTHER "X" FACTORS}

Nisbett: While the Black-White IQ gap is not due to some obvious factor such as Blacks not being familiar with formal English, or being less motivated to perform on IQ tests, or having teachers or IQ testers who have low expectations for their performance, there is plenty of evidence that
Blacks perform worse when their race is made salient because this engages a "stereotype threat." Blacks perform worse than they would in more relaxed settings where they need not fear they may be confirming a stereotype held by White testers. This was initially demonstrated by Steele and Aronson [65] and subsequently confirmed by countless studies. The underperformance is most likely when Blacks are tested in an integrated setting where intellectual ability is explicitly tested.

Another factor in the low IQ scores of Black Americans is what African anthropologist John Ogbu [66] has characterized as the effect of a "caste system" in America for Blacks. He refers to what he calls "involuntary minorities"-like the Africans who were brought to America by force. Ogbu argues that caste-like minorities often fail to take full advantage of the opportunities that are available to them because they lack conviction that their effort will be rewarded. Younger members of the minority may even invert the educational values of the society such as those among American Blacks who reject academic earnestness as "acting White." Ogbu points out that young Black students, even middleclass ones in middle-class schools, are more likely to come to class without having done their homework, and to be disruptive.

More generally, the problems that affect ability and achievement in lower-SES groups are often exacerbated for Blacks, who are overrepresented among the poor. These include poor prenatal care and nutrition, relative infrequency of breast-feeding, deficiency of vitamins and minerals, lead poisoning, fetal alcohol poisoning, poorer health care, greater exposure to asthma-causing pollution, emotional trauma, poor schools, poor neighborhoods along with the less desirable peers who come along with the territory, and much moving and consequent disruption of education. Moreover, Black parenting differs very much from White parenting in encouraging abstraction and cognitive ability. For example, by the time the child of White professionals is three years old, she has heard 500,000 encouragements and 80,000 discouragements. By contrast, the three-year-old Black child whose mother is on welfare has heard about 75,000 encouragements and 200,000 reprimands.

Rushton \& Jensen: Nisbett's critical variables were dubbed "X factors" by Jensen [21, p. 137] to dramatize their plausible but mysterious or not-yet-demonstrated character. One way to test whether hypothesized $\mathrm{X}$ factors are operating to lower IQ scores for Blacks on standardized tests is to compare the similarity of the correlations between background variables (such as the home environment or the peer group) and outcome measures (such as scholastic achievement or delinquency rates). If Black-specific $X$ factors are truly having an effect, some of these correlations for Blacks should be offset (up or down).

A series of studies on large samples by David Rowe [67] found no evidence of $X$ factors acting to lower the IQ scores of Blacks. For example, Rowe et al. [68] examined test scores for 8,528 Whites, 3,392 Blacks, 1,766 Hispanics, and 906 Asians and found the exact same relation between background variables (e.g., home environment, peer characteristics) and developmental outcomes (e.g., achievement, delinquency). Not only were the Black and White matrices nearly 
A
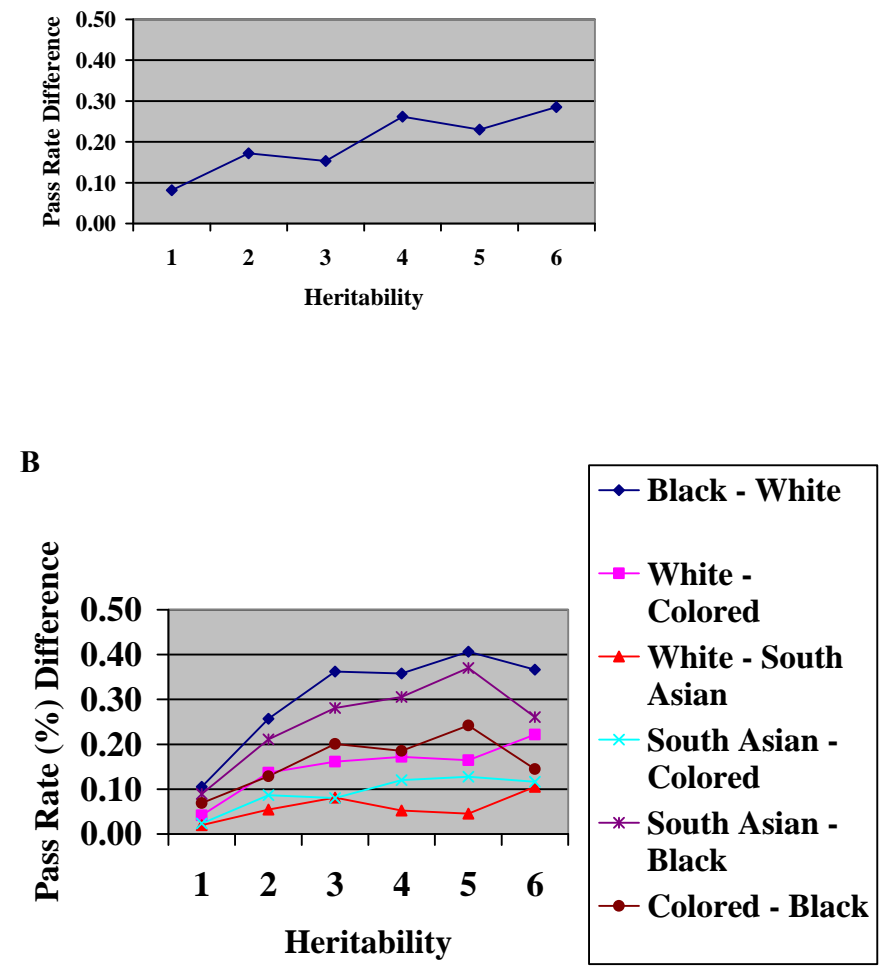

Fig. (3). Relation of heritability to mean group differences in pass rate for 6 parcels of items. (A) Canadian twins and Serbian Roma on Colored Progressive Matrices; (B) White, Asian, Colored, and Black high school students in South Africa on Standard Progressive Matrices. (Based on data from Rushton et al. [63]).

identical, they were as alike as the matrices computed from random halves within groups. There were no distortions in the correlations between the background variables and the outcome measures that suggested any minority-specific developmental factor.

Another study examined longitudinal data on academic achievement (Rowe et al. [69]). Correlations were computed between academic achievement and family environment measures in 565 full-sibling pairs (White $\mathrm{N}=296$ pairs; Black $=149$; Hispanic $=120$ ) from the National Longitudinal Survey of Youth tested at ages 6.6 and 9.0 years. Including age as a variable yielded three $8 \times 8$ correlation matrices. Analyses again showed the matrices were equivalent across the groups with no evidence of any Factor X affecting academic achievement or developmental changes of any group.

Virtually identical statistical structure across racial groups has also been reported in military samples. For example, Ree and Carretta [70] examined a nationally representative sample of young Black, White, and Hispanic men and women who took the Armed Services Vocational Aptitude Battery (ASVAB; $N=9,173$ ), which consists of 10 separately scored subtests. They found the hierarchical factor structure of ASVAB subtest scores was the same across the three groups. Similarly, Carretta and Ree [71] examined the more specialized and diverse Air Force Officer Qualifying Test (AFOQT), a multiple-aptitude battery given to 269,968 applicants (212,238 Whites, 32,798 Blacks, 12,647 Hispanics, 9,460 Asian Americans, and 2,551 Native Americans).
The same $g$ factor structure accounted for the greatest amount of variance in all groups with loadings differing little by ethnicity. There was no race-specific "Factor X" effect.

\section{REACTION TIME MEASURES}

Nisbett: Within race, those with higher IQ scores tend to have quicker reaction times. In addition, the variability of the reaction times for higher-IQ people tends to be more uniform. Although the correlations are low (.20) and not always found, the best bet is that there are weak associations. And, although reaction times and the variability of reaction times are longer and greater, respectively, for Blacks than for Whites, it is important to note that between-group differences do not necessarily have the same cause as withingroup differences. Because of the often conflicting nature of the results, it is best to assume that we know nothing of any clarity or value about the interrelations among reaction time, movement time, and race.

Rushton \& Jensen: Nisbett greatly understates the importance of reaction time (RT) tasks for the race-IQ debate and also ignores the data showing that East Asians have shorter RTs than Whites. The magnitude of the correlation between speed of reaction time and intelligence is much greater than the .20 claimed by Nisbett. While it is true that for any one task, the correlations between reaction time and IQ normally lie between .20 and .40 , when several measures are combined, multiple correlations are found of .60 to .70 [72-74]. Aggregating data is standard operating procedure in 
psychometrics, as for example when items and subtests are aggregated to find a total score on an IQ test.

Reaction times are measured on an absolute scale (i.e., one with a true zero) and indicate the neurophysiological efficiency of the brain's capacity to process information accurately, which is the same ability measured by intelligence tests [72-74]. Reaction time is one of the simplest culturefree measures. Many RT tasks are so easy that 9- to 12-yearold children can perform them in less than one second. Yet even on these very simple tests, children with higher IQ scores perform faster than do children with lower scores, and East Asian 9- to 12-year-olds are faster than Whites who are faster than Blacks. Moreover, the differences between Blacks, Whites, and East Asians in RTs are largely on the $g$ factor, with the correlations between the $g$ loadings and the mean group differences ranging from .70 to $.81[75,76]$. Since school children are not trained to perform well on reaction time tasks, as they are on certain paper-and-pencil tests, the advantage of those with higher IQ scores on RT tasks is unlikely to arise from practice, familiarity, education, or training. Moreover, although the East Asians averaged faster decision times than the Whites or the Blacks, the Blacks averaged faster movement times than the Whites or the East Asians, thereby eliminating the hypothesis that the differences on these tests reflect a difference in motivation.

Lynn and Vanhannen [13, pp. 66-67] observed the same pattern of RT scores internationally with over 1,000 9-yearold East Asian children in Japan and Hong Kong, White children in Britain and Ireland, and Black children in South Africa. The Progressive Matrices were given as a non-verbal test of intelligence, along with the "simple," "choice," and "odd-man-out" reaction time tasks. Table 3 shows the correlations between IQ and reaction times for the five countries. The East Asian children obtained the highest IQs, followed by the White children, and then the Black children. The median speed for the three reaction time tasks followed the same order, as did their SDs, with the highest scoring group being the least variable.

\section{WITHIN-RACE HERITABILITY}

Nisbett: Heritability measures the percentage of variation in a trait that can be attributed to the genes. The remain- ing percentage is due to all other factors such as prenatal and perinatal events as well as nutrition, education, and experience. Heritability is estimated by comparing the resemblance of family members raised together and apart, especially identical against fraternal twins, and adopted children against ordinary brothers and sisters. Identical twins share $100 \%$ of their genes, while fraternal twins only share $50 \%$, just like ordinary brothers and sisters, while adopted children share no genes. Some typical correlations are: identical twins reared together $(\mathrm{r}=.85)$, identical twins reared apart (.74), fraternal twins reared together (.59), siblings reared together (.46), siblings reared apart (.46), midparent/child together (.50), single parent/child together (.41), single parent/child apart (.24), adopting parent/child together (.20), and adopted children together (.26).

Using correlations such as these, it is also possible to distinguish between two different types of environmental effects. The shared environment (also called common or between-family or home environment) includes all those variables that children reared in the same family have in common (e.g., parental socioeconomic status and child-rearing style); they make children growing up in the same family similar to one another. The non-shared environment (also called within-family or specific environment) includes all those variables that are unique to each child (e.g., an illness or chance friendship or outstanding teacher experienced by one sibling but not the other); they make children growing up in the same family different from one another.

Many scientists today consider the heritability of IQ to be much lower than some previous estimates of 75 to $85 \%$. I (Nisbett) agree and suggest that the "true" heritability is lower than $50 \%$ because most studies are biased by the use of higher social-class samples. Even comparisons of identical twins reared apart over-estimate heritability because the twins initially shared the same uterine environment, an observation that led Devlin et al. [77] to argue that heritability estimates based on twins should be reduced by $20 \%$.

I (Nisbett) also suggest that common environment effects are higher than is often suggested. For example, adoption studies show that placing a child in an upper-middle-class environment rather than a lower-class environment results in an additional 12- to 18-IQ points - a truly massive effect.

Table 3. Sample size, Mean IQ Score, and Reaction Time Measures (in Milliseconds) from Five Countries

\begin{tabular}{|c|c|c|c|c|c|c|c|}
\hline & Hong Kong & Japan & Britain & Ireland & South Africa & SD & $r^{*}$ \\
\hline Sample size & 118 & 110 & 239 & 317 & 350 & - & - \\
\hline Simple reaction time & 361 & 348 & 371 & 388 & 398 & 64 & $.94 *$ \\
\hline Choice reaction time & 423 & 433 & 480 & 485 & 489 & 67 & $.89 *$ \\
\hline Variability of simple reaction time & 99 & 103 & 90 & 121 & 139 & 32 & $.83 *$ \\
\hline Variability of choice reaction time & 114 & 138 & 110 & 141 & 155 & 30 & $.73 *$ \\
\hline Variability of odd-man-out reaction time & 269 & 298 & 282 & 328 & 332 & 95 & $.85^{*}$ \\
\hline
\end{tabular}

Note. ${ }^{*} r=$ reliability. Adapted from "IQ and the Wealth of Nations," by R. Lynn and T. Vanhanen [13], , p. 67, Table 6.2. Reprinted with permission. 
Several adoption studies of this kind were carried out in France by Capron and Duyme [78, 79]. Thus, Duyme et al. [79] found that 4-year-old abused children with IQs of 75 gained 14 points after being adopted and retested at age 14 . Moreover, while children adopted into lower-SES families gained only 8 points, those adopted into middle-class families gained 16 points, and those adopted into upper-middleclass families gained almost 20 points. A review of adoption studies by van IJzendoorn et al. [80] estimated an 18-point IQ advantage for children adopted by upper-middle-class families compared to being raised in a lower SES family. They also estimated the genetic contribution to be at most about 12 points, derived by comparing the biological children against their adopted siblings. Earlier reviews, such as one by Herrnstein and Murray in The Bell Curve [7] greatly underestimated the magnitude of adoption on IQ, asserting it was only 6 points rather than the 12 points that most reviews of this literature find [81].

Rushton \& Jensen: Nisbett has highly skewed his conclusion by over-relying on data from young children. Evidence shows that heritability is lowest early in life and increases with age. By adulthood the heritability of IQ is from 60 to $80 \%$ [82]. Fig. (4) summarizes the changes with age due to genetic factors and shared and nonshared environments. It is based on an analysis of 6,370 identical and 7,212 fraternal twin pairs reared together [83]. As can be seen, the proportion of IQ variance associated with shared environmental factors is relatively constant at approximately $30 \%$ for ages up to 20 years but then drops to $0 \%$ in adulthood. Virtually identical results are found when studying non-twin relationships, such as parent-offspring correlations, including adopting parents and adopted children, and their adopted and biological siblings [84].

Although Nisbett reported as an error Herrnstein and Murray's conclusion that the effect size for adoption studies was only 6 rather than 12 IQ points, he failed to mention that Herrnstein and Murray [7, p.747, n. 86] went on to detail how even a 20 -point swing in IQ is consistent with their heritability estimate of 60 percent. This is because the re- maining $40 \%$ of the observed variation remains for environmental influence. Jensen [22] too showed how the typical gains of 10 to 12 points due to adoptions are readily compatible with high heritability. He further noted that although adoption studies demonstrate IQ gains, they typically fail to examine whether the gain is on the $g$ factor When Jensen [85] re-analyzed two of the data sets from Capron and Duyme (cited by Nisbett), he found that being adopted into high socioeconomic status (SES) homes produced a gain only in the non- $g$ factors of the various subtests. By contrast, the adopted children's $g$ factor scores mainly reflected the SES level of their biological parents, which implied that $g$ is less amenable to environmental manipulation.

\section{BETWEEN-RACE HERITABILITY}

Nisbett: Heritability places no theoretical limit on the degree to which IQ can be affected by the environment. I will present my case vividly. Imagine tossing the seeds for corn plants into either rich soil or poor soil. The average height of the two groups of plants would differ greatly and do so entirely due to environmental factors even though they were genetically identical. The case can also be shown empirically by juxtaposing two facts: (a) the heritability of height is 85 to $90 \%$, and (b) gains in height of a standard deviation or more have appeared in a generation or less in several countries of the world. For example, the average height of 13-year-old Korean boys increased by more than seven inches between 1965 and 2005, a difference of 2.4 SDs.

Most heritability studies have a middle-class bias and overestimate the heritability of IQ for poorer people and Blacks. For example, Turkheimer et al. [86] carried out a study of 319 pairs of 7-year-old twins and showed that heritabilities radically depend on social class. On the Wechsler Intelligence Scale for Children (WISC), the heritability of IQ was about $70 \%$ for children whose parents were uppermiddle-class but only about $10 \%$ for children whose parents were of lower social class (over half of them of AfricanAmerican descent). Earlier studies (cited by Turkheimer)

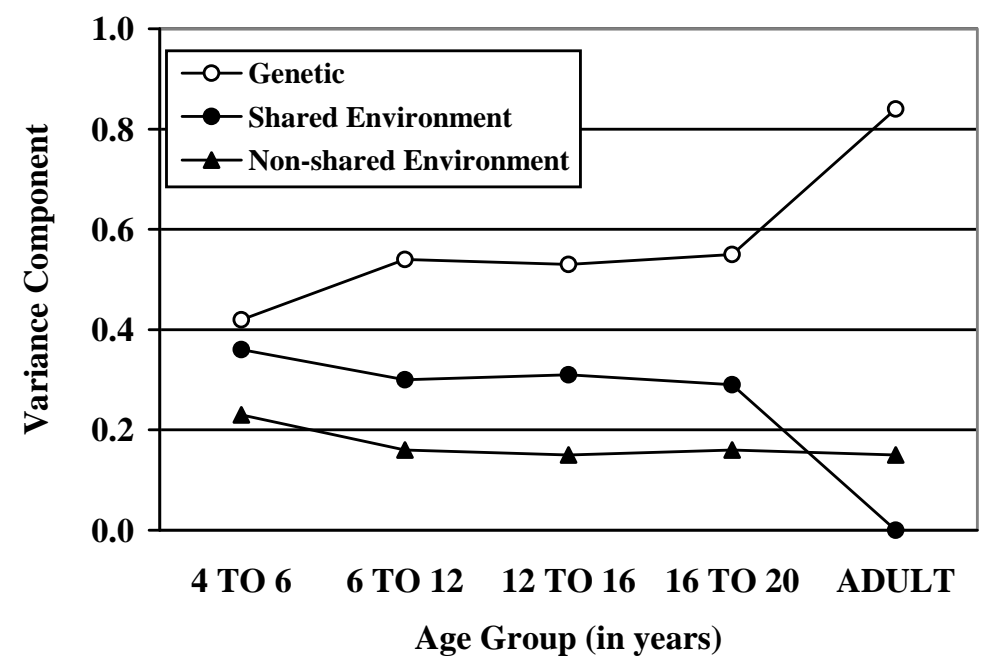

Fig. (4). Estimated proportions of the total IQ variance attributable to genetic and environmental (shared and nonshared) effects. Note that only the nonshared (or within family) environmental variance remains relatively constant across the entire age range. (From McGue et al. [83], p. 64). 
yielded similar results in terms of directionality, if not magnitude. The likely explanation is that lower-SES settings vary much more than middle-SES settings, including some that are pathological, thus causing the environmental effect to swamp heredity. By contrast, middle- to high-SES families do not differ much among themselves and provide sufficient conditions for the development of intelligence.

Dickens and Flynn [87] proposed a formal model that addressed the problem of gene-environment interaction. They showed that two groups could be separated by an environmental factor of great potency that did not affect each member of the groups equally. I (Nisbett) find it easy to imagine a variety of potent environmental factors that separate Blacks and Whites. For example, different child-rearing practices and different youth cultures could have a powerful effect on how much each group does "mental exercise" and thereby affect the cognitive problem-solving skills they each develop.

Rushton \& Jensen: Most heritability studies find IQ to be just as genetically influenced in non-White samples as in White samples [88]. There is little indication of any extreme deprivation, or special cultural influence-such as being raised as a visible minority - at work in one group and not in others. If Black heritabilities were consistently lower than White heritabilities, we would indeed conclude that poverty, the legacy of slavery, or White racism had operated to suppress the level of intelligence in Blacks. However, when Osborne [89] tested this hypothesis empirically by comparing several hundred pairs of Black and White twins aged 12to 18-years on the Basic Test Battery, the Primary Mental Abilities test, and the Cattell Culture Fair Intelligence test. $\mathrm{He}$ found heritabilities of about $50 \%$ in each group. The heritabilities in the Basic, Primary, and Cattell tests were, respectively: Whites-.61, .37, and .71; Blacks-.75, .42, and 19.

The Turkheimer et al. [86] study with 7-year-olds that Nisbett cites, and a subsequent study by Harden et al. [90] on young adolescents, did report gene $\mathrm{x}$ environment interactions such that genetic influences were weaker and shared environmental influences stronger for individuals from poorer homes compared to those from more affluent homes. However, most studies have found no interaction effects or interactions that vary unpredictably. For example, in Britain, the exact opposite interaction effect was found in over 2,000 pairs of 4-year-old twins, with greater heritability observed in high-risk environments [91]. In a re-analysis of the Hawaii Family Study of Cognition, Nagoshi and Johnson [92] found a null relationship between parental cognitive ability and offspring performance in families of different levels of socioeconomic status. In a Dutch study of 755 adult twins and their siblings, van der Sluis et al. [93] also found a null effect such that genetic effects were the same across all levels of social class.

Several studies have also found that heritability estimates are about the same both within- as well as between Black and White samples. These findings led Jensen [22, pp. 445446] to dub the "default hypothesis" as one in which the causes of the differences between groups are the same as those within a group and to contrast it with the dual hypothesis, which contends that within- and between-group differences have different, independent causes. For example,
Rowe and Cleveland [94] analyzed full- and half-siblings from the National Longitudinal Survey of Youth on three Peabody Achievement Tests. There were 161 pairs of Black full-sibs, 106 pairs of Black half-sibs, 314 pairs of White full-sibs, and 53 pairs of White half-sibs, with measures made of Mathematics and Reading. The best fitting model for all the data was one whereby the sources of the differences between individuals within race and the differences between races were the same- $-50 \%$ genetic and $50 \%$ environmental. Similarly, Jensen [22, p. 465] tested four alternative models on IQ data from 123 Black and 304 White pairs of 12- to 18-year-old twins. The combined "default" model of genetic and environmental factors fit the Black-White differences best, while the genetic-only and environmentalonly models were inadequate.

The Dickens and Flynn [87] gene $\mathrm{x}$ environment model that Nisbett cites cannot explain the Black-White IQ difference because the model implies that Blacks, relative to Whites, become increasingly disadvantaged during the developmental period from early childhood to maturity. Yet almost all the data show that the size of the Black-White IQ gap remains constant at $1 \mathrm{SD}$, with no significant change after about three years of age. The Dickens and Flynn models have also been criticized for having too many free parameters and for ignoring the cross-cultural generalizability of Black-White differences on the $g$ factor $[8,95,96]$.

\section{SUB-SAHARAN AFRICAN IQ SCORES}

Nisbett: Rushton and Jensen [8] claim that Blacks from sub-Saharan Africa have an IQ of 70, which is even lower than that for African Americans. However, an IQ of 70 for sub-Saharan Africans is desperately wrong. By Western standards it would imply that more than half the African population suffers from mental retardation. Lynn's compilation of studies showing an IQ of 70 has been seriously critiqued by Wicherts et al. [97, 98] who showed that Lynn excluded several studies showing higher IQs for Africans. Wicherts also showed that many of Lynn's studies relied on small, haphazard samples and used inappropriate norms. In any case, the tests measuring African IQ, such as the Progressive Matrices, are highly environmentally responsive. For example, Skuy et al. [99] found gains of 14 points for Africans after training on task relevant behavior, while Daley et al. [100] found a gain of 26 points after 14 years of schooling. Results such as these simply do not fit a genetically "fixed" IQ of 70.

Rushton \& Jensen: Wicherts et al.'s [97, 98] reanalyses of sub-Saharan African IQ only succeeded in raising the mean from 70 to 80 . On the Progressive Matrices, they raised the mean from 70 to 78 ; on other tests such as the Draw-A-Man test, the Kaufman Assessment Battery for Children, and the Wechsler scales, they raised the mean from 70 to 81 . So, even if it should turn out that the mean IQ for Africa is 80 rather than 70 , the difference between Africans and Whites would still be 1.25 SDs.

Regardless, Lynn [101, 102] has responded to Wicherts et al. [97, 98] showing that their reviews inappropriately eliminated some low scoring samples. Lynn concluded that the best estimate of African IQ remains 70. His conclusion was corroborated by the comparable differences he and Meisenberg found on tests of educational attainment [102]. 
For example, on the Trends in International Mathematics and Science Study (TIMSS), which is standardized with a mean of 500 and SD of 100 on representative samples of 14year-olds with $N \mathrm{~s}=2,000$ to 10,000 , African 14-year-olds score two SDs lower than their European counterparts. On the 2003 TIMMS, the results for England, Botswana, Ghana, and South Africa were 503, 355, 278, and 268, respectively. Overall, the TIMSS scores correlate .85 to .91 with the published national IQs.

The average IQ of 70 for sub-Saharan Africans is highly consistent and not due to a "fluke" or to sampling error. Lynn's [11, 14] reviews covered over two dozen studies from West, Central, East, and Southern Africa, all of which found a low average IQ. Some of these studies had quite large Ns. In Ghana, Glewwe and Jacoby [103] reported a World Bank study of 1,736 11- to 20-year-olds representative of the entire country, all of who had completed primary school, and half of who were attending middle-school. Their mean IQ on the Progressive Matrices was less than 70. In South Africa, Owen [104] examined 1,093 African high school students aged 15-16 years on the Standard Progressive Matrices for which Lynn calculated an IQ of either 63 or 74, depending on the correction for secular trends. Nor should there be any doubt as to the impartiality of the investigators of African IQ as they include both Africans such as Fred Zindi from the University of Zimbabwe [39] and nonhereditarians such as Robert Sternberg. For example, in Kenya, Sternberg and colleagues [105] administered the Progressive Matrices to 8512 - to 15-year-olds who scored an IQ equivalent of about 70. In Tanzania, Sternberg et al. [106] gave the Wisconsin Card Sorting Task to 358 11- to 13 -year-olds who received a score equivalent to the 5 th percentile on American norms (i.e., IQ =75). After training on how to solve problems like those on the test, the children's scores improved, but only to about the 9th percentile on American norms (IQ < 80).

Tests of university students confirm this pattern of results. One of us (JPR) traveled to South Africa to collect new IQ data from highly-select Black students at the prestigious University of the Witwatersrand in Johannesburg. Seven independent studies were published yielding a median IQ of 84 (range 77 to 103 ) [40, 41, 107]. Assuming that African university students score 1 SD (15 IQ points) above the mean of their population, as university students typically do, a median IQ of 84 is consistent with a general population mean of 70 . Other studies of university students have found a comparable IQ average of about 84 [108]. Studies conducted on the most select of all African university students, such as those in engineering schools, or on the basis of math and science competitions, find their average IQ is approximately 100 [41, 108]. Assuming such students score two SDs above their group average, as they do at the best universities in the US, this value too indicates an IQ of 70 for the general population.

\subsection{Mediated Learning}

We agree that mediated learning interventions can increase African IQ scores. Indeed, one of us (JPR) coauthored the study by Skuy et al. [99] that Nisbett cites. Although that intervention did raise the mean IQ of first-year African psychology students from 83 to 97 , that value is still low for students at a leading university. Further, a metaanalysis of the evidence shows that "coaching" or "teachingto-the-test" has the effect of denuding the test of its $g$ loading [109]. More generally, we take it as non-arguable that intervention strategies such as the elimination of tapeworms, improved nutrition, and provision of electricity, schools, and hospitals will raise test scores in Africa, as indeed they will anywhere that such deleterious conditions are found.

\subsection{Test Bias}

In regard to Nisbett's suggestion that test scores have a different meaning in Africa than elsewhere, the existence of such a bias would be confirmed if the test failed to predict performance for Africans. However, a review by Kendall et al. [110] demonstrated that test scores predicted school grades and job performance equally well for Africans as they do for non-Africans (i.e., .20 to .50). Similarly, in the Sternberg et al. [105] study of Kenyan 12- to 15-year-olds, the IQ scores predicted school grades with a mean $r=.40$. In the Rushton et al. [40, 41] studies of African and non-African university students, scores on one IQ test correlated with scores on another IQ test 3 months earlier (.60 for Africans; .70 for non-Africans) and with end-of-year-exam marks measured 3 months later (.34 for Africans; .28 for nonAfricans). The only demonstrable, reliable example of bias is the rather obvious one of vocabulary for groups whose first language is not English. Even here, however, language accounts for only about 7 IQ points (out of the 30 point difference).

\subsection{Mental Age}

One way to give context to an African IQ of 70 is to compare it against the worldwide IQ average of 90 rather than the European average of 100. (Mean IQs of 100 are found only for European, East Asian, and Jewish groups.) Another way to understand an African IQ of 70 is in terms of mental age - that is, the cognitive age equivalent of a person's IQ score. Nowadays, the concept of a mental age has been replaced by the use of standard scores based on the normal distribution, but mental age might provide a way to understand the low African IQ. If an average IQ of 100 for adult Whites is set at a mental age of 18 , with a normal range of from less than 16 years to over 20 years, then an average IQ of 70 for adult Africans would be equivalent to a mental age of about 13 years. This would make the normal range of mental ages found in Africa to be from less than 11 to almost 15 years. Eleven-year-olds, of course, are not retarded. They can drive cars, build houses, and work in factories if supervised properly, and can even become involved in warfare and organized crime.

\section{RACE DIFFERENCES IN BRAIN SIZE}

Nisbett: Rushton and Jensen claim that cranial capacity and brain size are correlated with intelligence and that Whites average a greater cranial capacity than Blacks. It is true that the correlation between brain size and IQ may be as high as .40 and that according to a number of studies, Blacks have smaller brains than Whites. However, a Black-White difference in brain size is not always found, as shown in a compilation of data from the National Aeronautics and Space Administration [111]. When brain size differences between 
Blacks and Whites are found, they may have environmental causes. Pregnant Black women, compared to pregnant White women, are more likely to have any number of conditions that result in a smaller brain size for their offspring, ranging from poor nutrition to alcohol use. Perinatal factors are also more negative for Blacks than for Whites and prematurity is associated with smaller brain and body size in babies [112]. It is only when babies are premature that the brains of Black babies are smaller than those of White babies [113]. Postnatal conditions also favor Whites over Blacks, especially for nutrition.

There are several other anomalies for the race/brainsize/IQ hypothesis. For example, the brain-size/IQ correlation has not been shown to be causal. If bigger brains were smarter because of their size, we would expect to find a correlation within families. Siblings who get larger brains by luck of the genetic draw should also be the ones who have higher IQ scores. In fact, however, there is no such correlation. Schoenemann et al. [114] found that the sibling with the larger brain has no higher IQ on average than the sibling with the smaller brain. Another anomaly is that Albert Einstein's brain was decidedly smaller, at 1,230 grams, than the overall average found for Blacks in the studies by Rushton. In Ecuador there exists a group of very short-stature individuals whose head size is several standard deviations below the mean [115]. These individuals have not merely normal intelligence but unusually high intelligence, with a majority being among the highest ranking in their school class.

Rushton \& Jensen: Larger brains are more intelligent because they contain more neurons and synapses and process information faster and more efficiently. Two dozen studies using magnetic resonance imaging (MRI) have shown that brain size is related to IQ with a correlation of about 40 . This is much higher than the .20 found using indirect head size measures, though that correlation is also reliable and significant [116]. Brain size is also highly heritable. An MRI study of 112 extended twin families found heritabilities of $82 \%$ for whole-brain gray matter volume, $87 \%$ for wholebrain white matter volume, $86 \%$ for IQ, and $100 \%$ for the relation between them (Posthuma et al. [117]). An MRI study of 46 pairs of twins found a high heritability for many specific connections within the brain, including myelin sheath, the fatty "insulation" that coats the axons and increases the speed of neural transmission [118].

Dozens of studies from the 1840 s to the present have demonstrated race differences in brain size whether measured by MRI, endocranial volume from empty skulls, brain weight at autopsy, or external head size (with or without corrections for body size). Rushton [23] averaged the data and found: East Asians $=1,364$ in $\mathrm{cm}^{3}$; Whites $=1,347$; and Blacks $=1,267$, with a standard deviation of about $10 \%$. Thus, the overall mean for East Asians was $17 \mathrm{~cm}^{3}$ more than that for Whites and $97 \mathrm{~cm}^{3}$ more than that for Blacks. Within-race differences due to differences in method of estimation averaged $31 \mathrm{~cm}^{3}$. Since 1 cubic centimeter of brain tissue contains millions of brain cells and billions of synapses, race differences in brain size help to explain their IQ differences. Indeed, if the racial differences in brain size did not relate to cognitive ability, it would be a mystery why such differences in number of neurons would ever have evolved since they are metabolically very expensive.

\subsection{Within-Family Studies}

Nisbett's citation of Schoenemann et al.'s [114] paper to support his claim of no within-family correlation between brain size and IQ is highly selective because five independent studies have now examined the within-family correlation between brain size and IQ [114, 119-122] and only Schoenemann et al. failed to find the relationship. The study used a small sample of 20 pairs of sisters with a restricted range of IQ, thus making it statistically more difficult to detect differences. The largest of the within-family studies measured head circumference at birth and IQ at age 18 at the time of conscription in the Swedish military [119]. The data were analyzed for 96,189 males who had at least 1 full brother similarly measured. These within-family comparisons are of special interest because they control for most of the sources of variance that distinguish families, such as social class, styles of child rearing, and general nutrition.

\subsection{MRI, Autopsy, Skull Size, and External Head Size Studies}

Using MRI, Harvey et al. [123] found that 41 Africans and West Indians in the United Kingdom had a smaller average brain volume than did 67 Caucasians (although Harvey et al. provided no details on how, or if, the samples had been matched for age, sex, or body size). In another British study, Jones et al. [124] found a (non significant) trend for AfroCaribbeans to average a $30 \mathrm{~cm}^{3}$ smaller intracranial volume and with larger ventricles than Whites. (Ventricles are areas in the brain filled with cerebral spinal fluid.)

When Paul Broca [125] measured brain weight at autopsy, he found Blacks averaged lighter brains than Whites and also had less complex convolutions and smaller frontal lobes. These results have been well replicated and a Black-White difference found of about 100 grams [126-129]. In a study of 1,261 American adults, Ho et al. [112] found that 450 Blacks averaged 1,223 grams and 811 Whites averaged 1,323 grams. Since the Blacks and the Whites were similar in body size, differences in body size cannot explain the differences in brain weight. The largest autopsy study, as yet unpublished, is by anthropologist Ralph Holloway who examined data from the Columbia University Medical School and from China [130]. He examined males and females aged 15 to 65 years and found that 615 Blacks, 153 Hispanics, 1,391 Whites, and 5,731 East Asians averaged brain weights of $1,222,1,253,1,285$, and 1,290 grams, respectively. The groups were of similar body size, except for the East Asians who were shorter in stature and lighter in weight.

The American anthropologist Samuel George Morton [131] filled over 1,000 skulls with packing material and found Blacks averaged five cubic inches $\left(80 \mathrm{~cm}^{3}\right)$ less cranial capacity than Whites. These results too have been well corroborated [132-134]. The largest study was by Beals et al. [135] which measured approximately 20,000 skulls from around the world. It found that Africans, Europeans, and East Asians averaged cranial volumes of $1,268,1,362$, and $1,415 \mathrm{~cm}^{3}$, respectively.

External head size measurements (length, width, height) have also been used to calculate cranial volume. Rushton [136] examined head size measures in 24 international mili- 
tary samples collated by the U.S. National Aeronautics and Space Administration (NASA) and found that after adjusting for the effects of body height, weight, and surface area, cranial capacity was $1,446 \mathrm{~cm}^{3}$ for Europeans and $1,460 \mathrm{~cm}^{3}$ for East Asians. Subsequently Rushton [137] calculated cranial capacities for Blacks, Whites, and East Asians from a stratified random sample of 6,325 U.S. Army personnel and found averages of $1,359,1,380$, and $1,416, \mathrm{~cm}^{3}$, respectively, even after controlling for all kinds of body size measures.

\subsection{Perinatal and Environmental Factors}

Nisbett attributed any brain size differences found between Blacks and Whites to perinatal factors and prematurity, as well as to poorer post-natal nutrition. But the evidence has never supported these long standing and reasonable hypotheses. For example, race differences in brain size can be observed before birth. In a study of fetuses, Schultz [138] found that from the 9th week of intrauterine life, 165 Black fetuses averaged a smaller brain case than did 455 White fetuses. The difference became more prominent over the course of fetal development.

Similarly, perinatal factors were ruled out as important for the development of IQ on the basis of a longitudinal study by the U. S. National Collaborative Perinatal Project of 40,000 children followed from birth to seven years [139, 140]. It showed that at birth, 4 months, 1 year, and 7 years, Black children averaged smaller cranial volumes (based on head circumference measures) than White children who averaged smaller cranial volumes than Black children (Fig. 5). Within each group, the children with the larger head sizes obtained the higher IQ scores (mean $r=.20$ ). The differences in brain size were not mere correlates of body size, and unlikely to be due to nutrition, since the Black children were the tallest in stature and heaviest in weight, while the East Asian children were the shortest in stature and lightest in weight.

\subsection{NASA, Einstein's Brain, and the Ecuadorean Sample}

Nisbett was highly selective in citing a compilation of data by NASA as evidence that Black populations do not always average a smaller brain than Whites, for the NASA data set contained only a single Black sample (454 African mine laborers from South Africa) with no variance and so no possibility of being statistically analyzed. Nor did Nisbett mention Rushton's [136] study that brought the NASA data to research attention showing that four samples of East Asian military personnel (from Korea and Vietnam) averaged larger crania $\left(1,460 \mathrm{~cm}^{3}\right)$ than did 20 samples of White military personnel $\left(1,446 \mathrm{~cm}^{3}\right)$ from the US, Canada, and Europe.

If Einstein's brain weighed 1,230 grams, that is indeed 10 grams below the mean of 1,240 grams for Blacks at autopsy [23]. However, Nisbett's reliance on a single vivid anecdote is misleading. Einstein was 76 years old when he died and the Black samples averaged 50 years younger. The aging process causes people to lose about 2 grams of brain tissue a year starting in the early twenties $[112,116]$. With regard to the Ecuadorean study, Nisbett is writing about a sample with Growth Hormone Receptor Deficiency (GHRD). However, he is mistaken as to their performance relative to the rest of the community for they perform at the same level as the rest of the community and similar to their relatives [141].
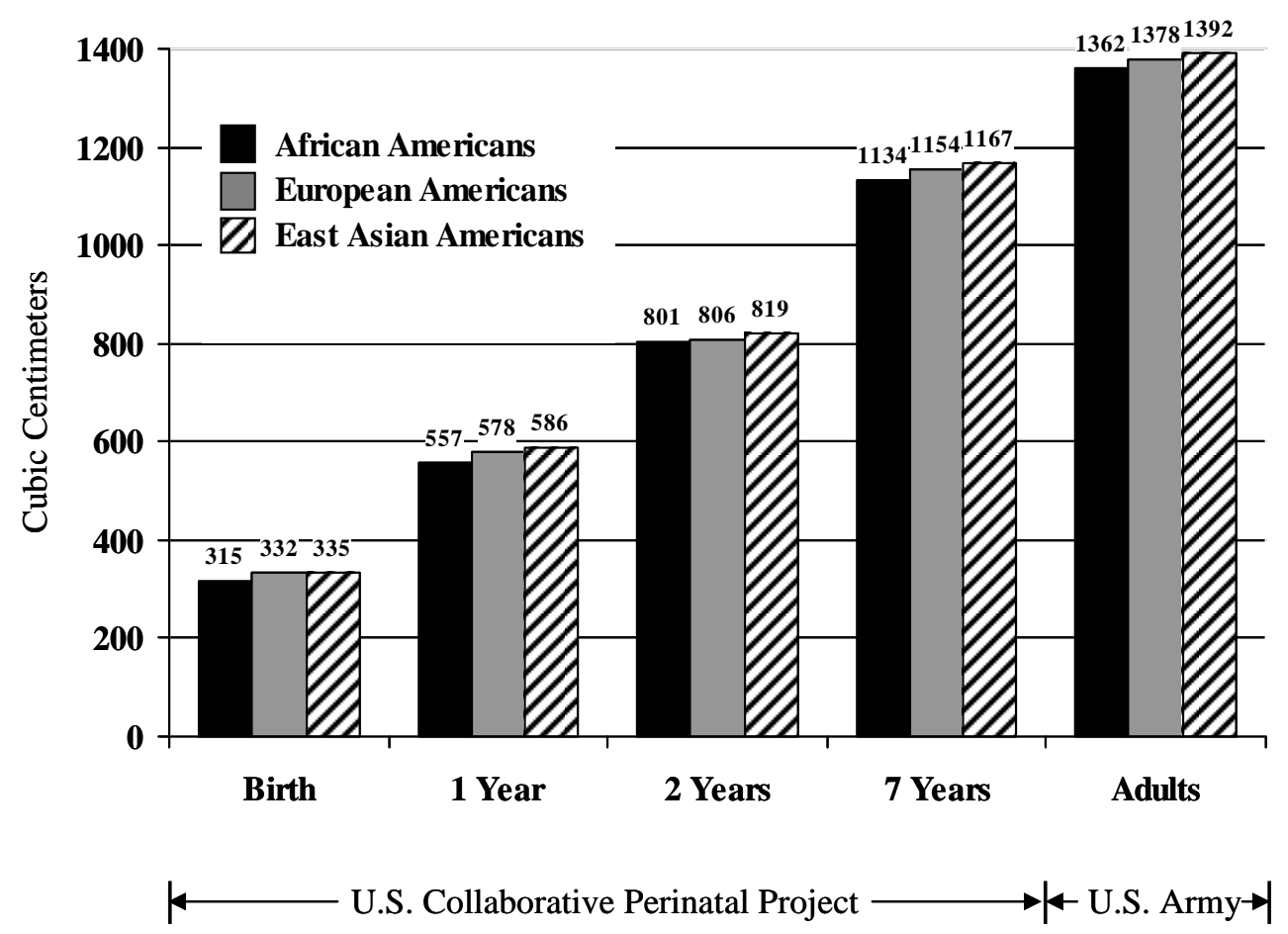

Fig. (5). Mean cranial capacity $\left(\mathrm{cm}^{3}\right)$ for African Americans, European Americans, and East Asian Americans from birth through adulthood. Data for birth through age 7 years from the U.S. Perinatal Project; data for adults from the U.S. Army data. (From Rushton [140], p. 15, Figure 2). 


\section{SEX DIFFERENCES IN BRAIN SIZE}

Nisbett: A brain size/IQ correlation found within the White population does not necessarily tell us about the reasons for the differences between Blacks and Whites. For example, Ankney [142] found that the male-female difference in cranial capacity is substantially larger than the Black-White difference. Yet, the genders have more or less the same IQ. So, why would any race difference in brain size really matter? In one sample of Blacks, Joiner [143] reported that the cranial capacity of Black females was the same as that of Whites, yet the IQ difference was the usual 1 SD.

Rushton \& Jensen: Nisbett is correct that relationships identified in one population do not necessarily tell us the reasons for the relationship in other populations. The sex difference in brain size is a good example and it presents a paradox. Ankney [142] did indeed find that adult males have heavier brains than adult females (by about 100 grams). He re-examined Ho et al.'s [112] autopsy data on 1,261 American adults and found that at any given body surface area or height, the brains of White men are heavier than those of White women, and the brains of Black men are heavier than those of Black women. For example, among Whites 168-cm $(5,7$ ') tall (the approximate overall mean height for men and women combined), the brain mass of men averaged about 100 grams heavier than that of women, whereas the average difference in brain mass, uncorrected for body size, was 140 grams. (Thus, about $30 \%$ of the sex difference in brain size was due to differences in body size).

Ankney's [142] results were confirmed by Rushton [137] in a study already mentioned in Section 9.2 of cranial capacity from a stratified random sample of 6,325 U.S. Army personnel. After adjusting for the effects of age, stature, weight, military rank, and race, men averaged $1,442 \mathrm{~cm}^{3}$ and women $1,332 \mathrm{~cm}^{3}$. This difference was found in all of the 20 or more separate analyses (shown in Fig. 6) conducted to rule out any body size effect, and was replicated across samples of East
Asians, Whites, and Blacks. Parenthetically, the East Asian women constituted the smallest sample $(N=132)$, and it is probably this that caused the "instability" in cranial size when some corrections were made for body size (Fig. 6). The sex difference of $110 \mathrm{~cm}^{3}$ found by Rushton from analysis of external head measurements is remarkably similar to the 100 grams obtained by Ankney from analysis of brain mass $\left(1 \mathrm{~cm}^{3}=1.036\right.$ grams $)$.

\subsection{Sex Differences in Cognitive Ability}

Since brain tissue is energetically expensive, men of all races must be able to do something better, cognitively speaking, than women. According to Kimura [144], on average, women excel in verbal ability, perceptual speed, and motor coordination within personal space, while men do better on various spatial tests and on tests of mathematical reasoning. A review by Voyer et al. [145] showed that on the "purest" spatial measures, such as rotating an imaginary object or shooting at a moving rather than a stationary target, the mean sex difference approaches 1 SD. Ankney [142] therefore hypothesized that the sex difference in brain size relates to those intellectual abilities at which men excel, such as spatial and mathematical abilities, which then may require more "brain power." Analogously to computers, whereas increasing word-processing power requires some extra capacity, increasing three-dimensional processing, as in graphics, requires a really substantial increase.

However, the finding that women have proportionately smaller average brains than men but apparently the same overall IQ test scores, led Lynn [146, 147] to offer a resolution of what he termed "the Ankney-Rushton anomaly" [147, p. 1]. He tested the 19th century proposition that men average slightly higher in general intelligence than women [148]. Reviewing data from Britain, Greece, China, Israel, the Netherlands, Norway, Sweden, Japan, India, Indonesia, and the US, Lynn found that men averaged about 4 IQ points

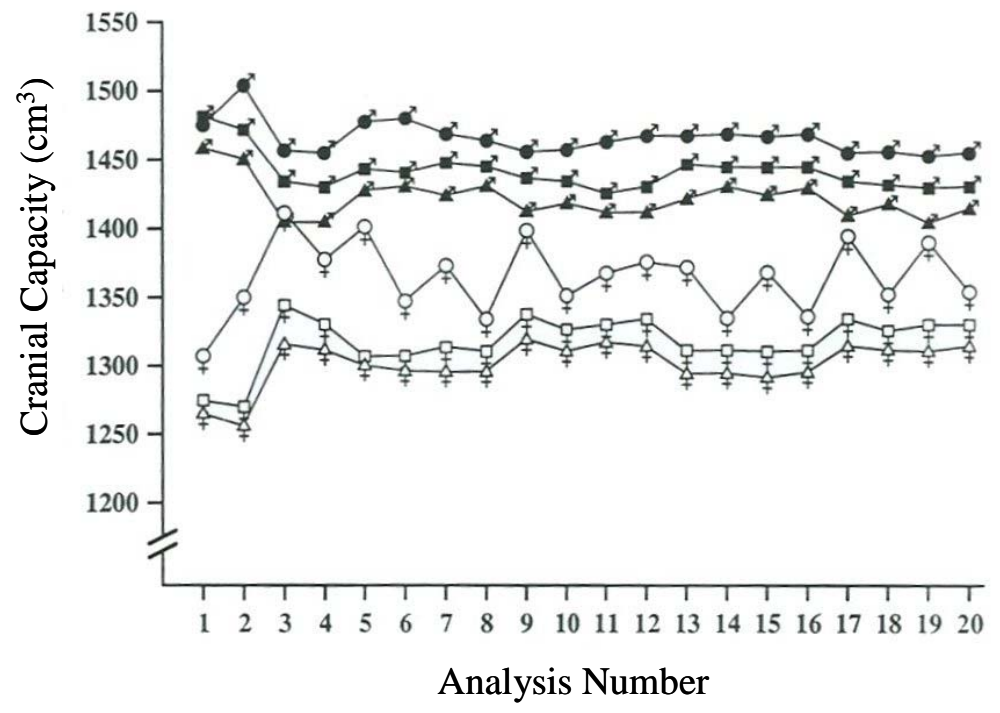

Fig. (6). Cranial capacity for a stratified random sample of 6,325 U.S. Army personnel. The data, grouped into six sex-by-race categories, are collapsed across military rank. (East Asian men, closed circles; white men, closed squares; black men, closed triangles; East Asian women, open circles; white women, open squares; black women, open triangles). They show that, across the 19 different analyses controlling for body size, men averaged larger cranial capacities than did women, and East Asians averaged larger than did whites or blacks. Analysis 1 presents the data unadjusted for body size showing no difference for East Asian and white men. (From Rushton [137], p. 408, Figure. 1). 
higher than women on a number of published tests. He suggested that age and development are critical because the male advantage in IQ does not emerge until the late adolescent growth spurt when brain size differences peak. Girls mature faster than boys, which give them an early advantage in language development and may mask later cognitive differences. Lynn argued this may have led generations of researchers, who relied on school samples, to miss the later emerging sex difference. Subsequently, in metaanalyses of general population samples on the Progressive Matrices, Lynn and Irwing [149, 151, 151] found no sex difference in IQ among children aged 6- to 14-years but a male advantage from 15-years through old age, with the male advantage by adulthood being equivalent to about 4.6 IQ points. Other researchers have corroborated Lynn's results $[152,153]$.

\subsection{Age $x$ Sex $x$ Race Interactions}

Nisbett cited a study by Joiner [143] that found Black females had equal or larger crania than White females but a lower IQ score. Nisbett used this finding to cast doubt on the causal relationship between race, brain size, and IQ. He failed to mention that Joiner's sample was of 12- to 18-yearolds who had previously been analyzed by Rushton and Osborne [154] in a study of the heritability of cranial capacity in which an age $x$ sex $x$ race interaction found that girls matured earlier than boys and Blacks matured earlier than Whites, resulting in young Black girls being larger in body (and head) size than their White counterparts. However, by the end of the adolescent growth spurt, the typical race $\mathrm{x}$ sex pattern of differences clearly emerges (Fig. 6). The disordinal age $\mathrm{x}$ sex $\mathrm{x}$ race interactions have been found for samples of 7- to 17-year-olds since 1899 [155].

\section{TRANS-RACIAL ADOPTION STUDIES}

Nisbett: Rushton and Jensen [8] claimed that a study by Scarr and Weinberg [156] showed that the IQs of Black and Mixed-Race children adopted by upper-middle-class White families averaged little different from those of their counterparts in the population at large, and that the IQ of the MixedRace children averaged in between those of Blacks and Whites. When the children were about 7-years-old, the results suggested a small genetic contribution to the BlackWhite IQ gap. When they were adolescents, the data suggested a larger genetic contribution to the gap [157].

However, Scarr and Weinberg [156] identified several flaws in their study which made it non-supportive of a hereditarian position. To begin with there were no IQ measurements of the adopted children's biological parents making it impossible to know whether the children were assigned selectively, for example, by putting the Black adoptees into families that were of relatively lower social class. Moreover, the Black children were adopted at a later age than were the Mixed-Race children, and later age at adoption is associated with lower IQ. Also, the Black children had more prior placements in foster homes, which is also associated with lower IQ. By adolescence, the Black and Mixed-Race children had a high level of psychological disturbance having to do with identity issues. As a consequence of all these problems, the authors cautioned against any conclusion with respect to the role of heredity for the race differences.
Moreover, there are at least two other studies that work against the hereditarian perspective. In a British study, Tizard et al. [158] examined Black, Mixed-Race, and White children raised in an excellent residential nursery school and found that at 4- to 5-years, the White children averaged an IQ of 103; the Mixed-Race children, 106; and the Black children, 108. On their face, these results seem compatible with the assumption of a nontrivial genetic advantage for Blacks. In a U.S. study, Moore [159] compared Black and Mixed-Race children raised in either Black or White middleclass adoptive families. The children raised by the Black mothers were found to have lower scores (IQ = 104) than those adopted by the White mothers (IQ = 117), which strongly implies that the gap is environmental in nature because under the genetic assumption, it should make little difference whether children are raised in Black or in White families.

Rushton \& Jensen: Trans-racial adoption studies provide one of the most powerful methods for studying race differences. Human adoption is clearly a massive environmental intervention and Nisbett rightly emphasized its importance when he discussed within-race adoptions (Section 6 ). We placed greatest weight on the Minnesota Trans-Racial Adoption Study because it is the largest and best-known of these studies and is the only one that included a longitudinal follow-up, with testing of the same children at ages 7 and 17 years $[156,157]$. It compared the IQ and academic achievement scores of Black, White, and Mixed-Race children who were adopted into upper-middle-class White families in Minnesota, whose parents had a mean IQ of 120 (much higher than the population mean of 100). The biological children of the adopting parents were also tested.

The first testing of 265 children was carried out in 1975 when they were 7-years-old and the second in 1986 when they were 17-years-old. Table 4 gives the results. The evidence for genetic influences became more evident as the children grew older. At age 17 adopted White children had an average IQ of about 106; Mixed-Race adoptees, 99; and adopted Blacks, 89. Although the Black mean of 89 was slightly above the national Black mean of 85 , it was not above the Black mean for Minnesota. Further, school grades, class ranks, and aptitude tests also showed this same pattern. Growing up in a White middle-class home produced little or no lasting increase in the IQs of the adopted Black children.

Nor are the findings for the Mixed-Race children likely due to lighter-skinned African Americans being treated better through "expectancy effects" or "labeling theory," as Nisbett implies they might be. For example, at age seven, Scarr and Weinberg [156] noted that some children were misclassified, with their adoptive parents wrongly believing that the mixed-race children had two Black biological parents. Yet these children averaged the same IQs as those of other Mixed-Race children correctly believed by their adoptive parents to have had one Black and one White biological parent.

The results cited by Nisbett of Tizard's [158] British study of 852 - to 5-year-old Black, White, and Mixed-Race children, and Moore's [159] study of 46 7-year-old Black adopted children are accurate, but to be fully informative they need to be supplemented by follow-up testing past ado- 
Table 4. Comparison of Cognitive Performance Measures at Ages 7 and 17 in Biological and Adopted (White, Mixed-Race, and Black) Children, all Reared in Middle-Class White Families

\begin{tabular}{|c|c|c|c|c|c|}
\hline $\begin{array}{l}\text { Nonadopted, with two White biological parents } \\
(N \text { at } 7=143 ; N \text { at } 17=104)\end{array}$ & 116 & 109 & 3.0 & 64 & 69 \\
\hline $\begin{array}{l}\text { Adopted, with one White and one Black biological } \\
\text { parent }(N \text { at } 7=68 ; N \text { at } 17=55)\end{array}$ & 109 & 99 & 2.2 & 40 & 53 \\
\hline $\begin{array}{l}\text { Adopted, with two Black biological parents } \\
(N \text { at } 7=29 ; N \text { at } 17=21)\end{array}$ & 97 & 89 & 2.1 & 36 & 42 \\
\hline
\end{tabular}

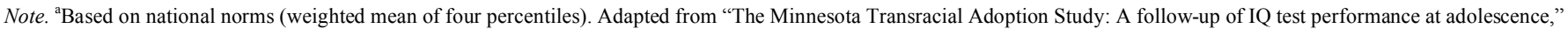
by R.A. Weinberg et al. [157].

lescence as in the Minnesota Study. As shown in Fig. (4), behavior genetic studies demonstrate that as people age their genes exert ever more influence, whereas family socialization effects decrease.

Nisbett omitted to mention three adoption studies of severely malnourished, late adopted, East Asian children by White families, which support the hereditarian model of a three-step racial gradient. Winick et al. [160] studied 141 Korean children malnourished-in-infancy and then adopted as infants by American families. They found that by 10 years of age the children exceeded the national average in IQ and achievement scores: A severely-malnourished group obtained a mean IQ of 102; a moderately-nourished group obtained a mean IQ of 106; and an adequately-nourished group obtained a mean IQ of 112. Clark and Hanisee [161] studied 25 4-year-olds from Vietnam, Korea, Cambodia, and Thailand who were adopted into White American homes before three years of age. Prior to placement, half the babies required hospitalization for malnutrition. When tested at age 4, their mean IQ score was 120 compared to the U.S. norm of 100. Frydman and Lynn [162] studied 19 Korean infants adopted by families in Belgium. At about 10 years of age, their mean IQ was 119 , their verbal IQ was 111 , and their performance IQ was 124. Even correcting the Belgian norms upward to 109 to account for any increase in IQ scores over time, the Korean children still had a statistically significant 10-point IQ advantage over indigenous Belgian children. Neither the social class of the adopting parents, nor the number of years the child spent in the adopted family, had any effect on the child's IQ.

\section{RACIAL ADMIXTURE STUDIES}

Nisbett: Rushton and Jensen [8] failed to deal fully with the most direct genetic evidence-the racial ancestry of a given individual. Since the genes in the U.S. Black population are about 20\% European [163], the hereditarian model predicts that Blacks with more European genes should have higher IQs. However, the review of studies on skin color by Shuey [6] showed only a .10 to .15 correlation, not those of the .20 to .30 or higher that might have been expected under the hypothesis (assuming we ignore the social advantages that accrue to Blacks with lighter skin). Moreover, studies of blood groups, some of which are common in European populations and rare in African populations, and vice versa, show no relation with African American IQ scores [164, 165].

Other studies have also examined the effects of racial ancestry and need to be taken into account. Eyferth [166], a German psychologist, studied the IQs of several hundred illegitimate children of German women fathered by Black American GIs during the post-World War II (1945) occupation, and compared them to those fathered by White GIs. The children fathered by the Black GIs had an average IQ of 96.5 and the children fathered by the White GIs had an average IQ of 97.

Another study identified 63 Black Chicago school children with IQs of 125 or above, and 28 children with IQs of 140 or above, asked them to report their racial inheritance $[167,168]$. These children reported slightly less European ancestry than the best estimate for the Black population as a whole. There is also a study of 4-year-old Mixed-Race children born to White versus Black mothers by Willerman et al. [169]. It found the children of White mothers and Black fathers had a 9-point IQ advantage over those of Black mothers and White fathers (mean IQs $=102,93 ; N \mathrm{~s}=101$, 28). This is contrary to the hereditarian prediction that children of mixed-parentage should have the same average IQ regardless of which parent is Black, In another study, Moore [159] examined a small number of 7-year-olds adopted by middle-class White parents which found no difference in IQ between the 9 children with two Black biological parents and the 14 with one Black and one White biological parent (IQs $=109,107$, respectively).

Finally, the reason Rushton and Jensen [8] give for African Americans having an average IQ of 85 rather than 70 is their $20 \%$ European admixture. Following the simplest version of this logic, if the admixture of European genes in the Black population were $60 \%$ instead of $20 \%$, then African 
Americans would have an average IQ of 115 ! This is simply not logical.

Rushton \& Jensen: Nisbett's citations of what he terms "direct evidence" for the nil heritability of Black-White IQ differences are peculiarly old. The median year of publication being 1960 (range 1934 to 1986). Most are weak and non-decisive and have not been replicated even once. Some are so old and recycled that Jensen [21] and Loehlin [2] dealt with them 35 years ago! Nisbett's account ignored several more recent studies. Here we will consider the skin color studies, Eyferth's German study and the others of MixedRace children, blood groups and DNA, and the Mixed-Race population of South Africa.

\subsection{Skin Color Studies}

Rowe [67] updated Shuey's [6] review showing that lighter-skinned African Americans average higher IQs than their darker-skinned counterparts. For example, Lynn [170] examined the National Opinion Research Center (NORC) survey of a representative sample of the adult population. The 442 Blacks were asked whether they would describe themselves as "very dark," "dark brown," "medium brown," "light brown," or "very light." The correlation between these self-ratings and a 10-word vocabulary test score was $.17(P<$ $.01)$. Similarly, Rowe [171] examined the National Longitudinal Study of Adolescent Health and found the Black adolescents averaged a lower verbal IQ than the White adolescents, with the Mixed-Race group falling in between.

Early studies of brain weight data also fit the genetic admixture hypothesis. Bean [126] found, as did Pearl [128], that among Blacks the greater the amount of White admixture (judged independently from skin color), the higher the mean brain weight at autopsy. Subsequently, Rushton [140] examined 37 East-Asian-European hybrids from the U.S. National Collaborative Perinatal Project and found they fell intermediate in brain size and IQ to the non-mixed parental groups.

A more general relation between IQ and skin color has been described by Donald Templer and colleagues [172175]. Templer found IQ correlated with expert ratings of skin color across 129 countries $(r=-.92$; the higher the IQ, the darker the skin). The correlation between IQ and skin color remained even when calculated separately within each of three continents: Africa, -.86; Asia, -.55; Europe, -.63. Moreover, Templer [174] found the ratings of skin color and actual skin reflectance measures correlated with each -.96 and both correlated with IQ scores about .90 , while absolute latitude correlated -.88 with skin color and .78 with IQ, as with mean winter temperature $(r=.71)$. He conceptualized skin color as a multi-generational adaptation to differences in climate in which colder climate selected for higher intelligence because of the greater cognitive requirements for obtaining food and protection from the elements (see also Section 14). Subsequently, Jensen [176] suggested the high correlation between IQ and skin color might be due to pleiotropy, in which a single gene has two or more phenotypic effects. In this regard, it would be informative to examine sibling data on IQ, brain size, and skin color. Do siblings who are lighter in skin color have larger brains and higher IQ than those who are darker?

\subsection{Eyferth's German Study}

Three studies of racially mixed individuals at first appear to support culture-only theory against the genetic hypothesis. Eyferth [166] reported IQ data for out-of-wedlock children fathered by soldiers stationed in Germany after World War II and then reared by White German mothers. The mean IQs for 83 White children and for 98 Mixed-Race children were both about 97 (97.2 for the Whites, 96.5 for the MixedRace). However, as Loehlin et al. [2, pp. 126-128] noted, these results are ambiguous for three reasons. First, the children were still very young when tested, with one-third between 5 and 10 years, and two-thirds between 10 and 13 . As shown in Fig. (4), behavior genetic studies show that while family socialization effects on IQ are often strong before puberty, after puberty they dwindle, sometimes to zero. Second, the Black GIs were almost certainly higher in IQ than average because at that time there was rigorous selection in the U.S. Army with a rejection rate for Blacks on the preinduction Army General Classification Test of about 30\%, compared to $3 \%$ for Whites. Third, 20 to $25 \%$ of the "Black" fathers were not in fact African Americans but French North Africans, that is, Caucasians.

Nisbett's citation of Willerman et al.'s [169] report of a 9-point IQ advantage for the 4-year-old offspring of couples with a White mother and a Black father compared to those from the offspring of a Black mother and a White father is very weak evidence. Thirty-five years ago, Loehlin et al. [2, p. 126] pointed out that the White mothers averaged almost a year more schooling than the Black mothers and so likely had a higher IQ. Nisbett also neglected to mention that the two sets of Mixed-Race children averaged an IQ of 98, intermediate to the White and Black children in the larger sample from whom they had been drawn (IQs = 105 and 91, respectively; [177, p. 43]. Similarly, with regard to Moore's [159] study which found no difference between 7-year-old adopted children with only one versus two Black biological parents, a follow-up to adolescence is really necessary to be informative.

\subsection{Blood Groups and DNA}

As Nisbett correctly surmised, existing studies of blood groups by Loehlin et al. [2] and Scarr et al. [165] provided no support for the hereditarian perspective because the blood groups that distinguish African from European ancestry did not predict IQ scores in Black samples. However, the genetic markers used turned out to have too little variation in allele frequencies to make detection likely between Africans and Europeans [22, pp. 480, 524 n.64]. Molecular genetic technology was far less sophisticated in the 1970s than it is today. In future studies, individual admixture should be calculated through the use of DNA markers, as is already done in medicine. McKeigue [178] has shown how admixture mapping has greater statistical power than family-linkage studies, requiring far fewer markers. On the basis of existing surveys, an individual's racial group can be determined by testing his or her DNA at 100 random sites along the genome, or at 30 specifically chosen ones [179]. Even different ethnic groups within a race can be distinguished using some 50 specifically chosen sites. 
There are still some who maintain that "races" do not exist at the genetic level. Tang et al.'s [180] study of 3,636 individuals who donated a DNA sample and identified themselves as being White, East Asian, African-American, or Hispanic argues strongly against this popular, though misinformed, contention. The study found that the selfidentifications clustered almost perfectly according to 326 measured DNA markers. There were only five individuals with DNA that matched a racial/ethnic group other than the one they had checked to classify themselves. That is an error rate of only 0.14 percent. Tang et al. [180] concluded that, "ancient geographic ancestry, which is highly correlated with self-identified race/ethnicity - as opposed to current residence - is the major determinant of genetic structure in the U.S. population" (p. 268).

\subsection{The South African "Coloreds"}

Nisbett is correct that Black Americans average a higher IQ than sub-Saharan Africans because of their 20 to $25 \%$ White admixtures. However, Nisbett failed to mention the support that also comes from South Africa where the MixedRace population known as the "Coloreds" (their preferred term) has an average IQ of 85 , intermediate to the respective African and White means of 70 and 100 [107]. The clear prediction is that other admixed groups will fall intermediate to the two parental populations.

\section{REGRESSION TO THE MEAN EFFECTS}

Nisbett: Rushton and Jensen [8] claim that because IQ is lower on average for Blacks than for Whites for genetic reasons, the Black children of high IQ parents should regress to a lower mean than White children of similar parents. And it apparently is the case that Black children of high IQ parents average lower in IQ than do White children of similar high IQ parents. However, this argument is quite weak because the same prediction can be derived from culture-only theory. If environmental factors such as parenting practices and subcultural pressures toward low intellectual performances are pushing the average Black IQ further down than the average White IQ, then we would expect more regression for Blacks - for reasons that have nothing to do with genetics.

Rushton \& Jensen: Nisbett has misunderstood the theory of genetic regression, which also predicts that the offspring of very low IQ parents will go up in IQ. This is because parents pass on some, but not all, of their exceptional genes to their offspring. It is analogous to rolling a pair of dice and having them come up two 6's or two 1's. The odds are that the next roll will produce a value that is not quite as high (or as low).

Black children with parents of IQ 70 regress upwards to their population average of 85 , just as much as do Black children with parents of IQ 115 regress downwards. Similarly, White children with parents of IQ 70 regress upwards to their population average of 100 , just as much as White children with parents of IQ 115 regress downwards. Regression helps to explain why Black children born to welleducated, affluent, parents have test scores 2 to 4 points lower than do White children born to poorly-educated, impoverished, parents. The Black children are simply regressing to a lower genetic mean.
Siblings provide an even better comparison than parent-offspring comparisons because siblings share very similar environments. Genetic theory predicts the precise magnitude of the regression effect. In one study, Jensen [21] tested the regression predictions using data from 900 White sibling pairs and 500 Black sibling pairs. When Black and White children were matched for IQs of 120, the siblings of Black children averaged close to 100, while the siblings of White children averaged close to 110 . A converse effect was also found for children matched at the lower end of the IQ scale. When Black and White children were matched for IQs of 70, the siblings of the Black children averaged about 78, while the siblings of the White children averaged about 85 . Throughout the range of IQs from 50 to 150 the results were exactly as predicted by genetic theory, not by culture-only theory.

\section{HUMAN ORIGINS AND LIFE HISTORY TRAITS}

Nisbett: The direction of recent evolution over the last few thousand years is toward smaller brain sizes for humans $[135,181]$.

Rushton \& Jensen: Nisbett's assertion is highly misleading. According to analyses by Ruff and colleagues [182, $183]$, any decrease in average brain size over the past 35,000 years within Homo sapiens has been paralleled by a corresponding decrease in average body size, suggesting no decrease in relative encephalization. (Ruff et al. also debunked the notion that Neanderthals, a late archaic H. sapiens, averaged larger crania than anatomically modern humans. Since Neanderthals had very robust bodies, about $10 \%$ larger than modern humans, their brain mass was slightly smaller relative to body mass.)

The hominid brain has tripled in size over the last 3 million years from Australopithecus to Homo erectus to modern humans [116, 182, 184]. In fact, neural complexity and brain size have been increasing in vertebrates and invertebrates alike over the last 575 million years, little of which can be explained by body size $[116,185]$. Encephalization quotients (EQs), a measure of brain size to body size $[\mathrm{EQ}=$ Cranial capacity $\left(\mathrm{cm}^{3}\right) /(.12)$ (body weight in grams) $\left.)^{.67}\right]$, average about .30 for mammals living 65 million years ago compared to 1.00 today. EQs for mollusks vary between .043 and .31 , and for insects between .008 and .045 , with the less encephalized species more resembling forms that appeared early in the geologic record and the more encephalized species, those that appeared later.

Metabolically, brain tissue is expensive. Representing only $2 \%$ of body mass, the brain uses about $5 \%$ of basal metabolic rate in rats, cats, and dogs, about $10 \%$ in rhesus monkeys and other primates, and about $20 \%$ in humans. Larger brains are also expensive in life-history trade-offs. They require more time to grow and larger bodies to produce and sustain them. From an adaptationist perspective, unless large brains substantially contributed to evolutionary fitness (defined as increased survival of genes through successive generations), they would not have evolved. In the evolutionary competition to find and fill new niches, there is always "room at the top" for larger brains and greater behavioral complexity. 
A basic law of evolution links brain size to what Wilson [186] termed $r-K$ Life-History Theory. This refers to a genetically organized group of traits that evolved together to meet the trials of life -- survival, growth, and reproduction. The term $r$ stands for the natural rate of reproduction (the number of offspring) and $K$ stands for the amount of care parents give to insure that their offspring survive. Plants and animals have different life-histories. Some are more $r$ and others more $K$, which are sometimes referred to as "fast" and "slow" life-histories, respectively, because of the different speeds of development they entail.

The bigger an animal's brain, the longer it takes to reach sexual maturity and the fewer offspring it produces. Oysters, for example, have a nervous system so simple that they lack a true brain. To offset this they produce 500 million eggs a year. In contrast, chimpanzees have large brains but give birth to one baby about every four years. The number of offspring, time between births, the amount of care parents give, infant mortality, speed of maturity, life span, even social organization and altruism all work together like pieces of a puzzle.

Rushton [187] found empirical support for the predicted relationships across 234 mammalian species: brain weight correlated with longevity $(r=.70)$, gestation time (.72), birth weight (.44), litter size (-.43), age at first mating (.63), duration of lactation (.62), body weight (.44), and body length (.54). Even after controlling for body weight and body length, brain size continued to predict the other variables $(r=$ .59). Among a narrower range of 21 primate species, brain size still correlated .80 to .90 with life span, length of gestation, age of weaning, age of eruption of first molar, age at complete dentition, age at sexual maturity, inter-birth interval, and body weight.

In Race, Evolution, and Behavior, Rushton [23] documented that the races differed not only in brain size and intelligence but also on a suite of 60 life-history characters (Table 5). People of East Asian and African ancestry fall at the two ends of a continuum, with Europeans falling intermediate in speed of maturation and longevity, personality and temperament, family stability and crime, and sexual behavior and fertility [23]. Consider two-egg twinning, which is based on a double ovulation and leads to faster (typically non-twin) pregnancy. It is striking that around the world the rate of dizygotic (also termed two-egg, fraternal, or nonidentical) twinning is: less than 4 per 1,000 births among East Asians; 8 among Whites; 16 or greater among Blacks. The tendency to produce dizygotic twins is heritable through the race of the mother and is mediated by sex hormones [23, $188]$.

Another example: Black babies sit, crawl, walk, and put on their clothes earlier than do White or East Asian babies. The milestones for walking are: East Asians, 13 months; Whites, 12 months; Blacks, 11 months. Blacks also average an earlier age of sexual maturity than do Whites, who in turn have an earlier age than do East Asians, whether measured by age of first menstruation, first sexual experience, or first pregnancy [23]. These racial-group differences are heritable: mixed-race children of Japanese-Black ancestry develop faster than do mixed-race Japanese-White children and especially than do children with two Japanese parents [189].
The fast-slow $r$ - $K$ life-history perspective fits with the current view of human origins, the "out-of-Africa" theory [23]. This posits that Homo sapiens arose in Africa about 150,000 years ago and then expanded northward beyond Africa about 100,000 years ago, with a European-East Asian split about 41,000 years ago. Evolutionary selection pressures were different in the hot savanna, where Africans evolved, than in the cold northern regions Europeans experienced, or the even colder Arctic regions where East Asians evolved. According to Bailey and Geary [184], cranial capacity increases linearly with degree of latitudinal deviation north from the equator $(r=.60)$, with $87 \%$ of the latitudinal variation predicted by differences in mean annual temperatures. Thus, the further north the ancestral populations migrated out of Africa, the more they encountered the more cognitively-demanding problems of gathering and storing food, gaining shelter, making clothes, and raising children successfully during prolonged winters. As these populations evolved into present-day East Asians and Europeans, the ecological pressures selected for larger brains, slower rates of maturation, and lower levels of sex hormone, and all the other life history characteristics [23]. No non-evolutionary theory can explain all the variables in the three-step racial gradient.

\section{GENERAL DISCUSSION}

Nisbett: We can now shake off the yoke of hereditarianism in all of our thinking about intelligence. Believing that our intelligence is substantially under our control would not make us smart by itself. But it's a good start. Since schools make children smarter, there is no doubt that better schools can make us smarter still.

While it is true that intelligence is partially heritable, and that more intelligent people will be, on average, of a higher social class in virtue of their greater inherited intelligence, I believe the role of genetic inheritance in determining social class is fairly small. For the race differences in IQ, we can be confident that genes play no role whatsoever. Believing intelligence is under your control-and having parents who demand achievement - can do wonders. At any rate that has been true for East Asians and Jews. And, even though East Asians outperform Europeans in educational achievement, there is no reliable evidence of a genetic difference in IQ between East Asians and Europeans. For example, on the 1999 TIMMS assessments, U.S. eighth-graders scored .75 to 1.0 SD below Japan, Korea, China, Taiwan, Singapore, and Hong Kong in math and .33 to .50 below these countries in science. However, these differences are due to family upbringing, the educational system, and achievement motivation. For the remaining differences between Blacks and Whites, genes account for none of it; the evidence favors a completely environmental explanation.

Rushton \& Jensen: The more we read Intelligence and How to Get It, the more we came to see it as a work not of scholarship, but of advocacy. Sadly, it is not the case that Nisbett simply sees the evidence differently than we do, or even favors his interpretation over ours when the evidence is mixed or ambiguous. Rather, he did his readers and the field a disservice by misrepresenting much of the available information. 
Table 5. Life History Traits between East Asians, Europeans, and Africans

\begin{tabular}{|c|c|c|c|}
\hline Trait & East Asians & Whites & Blacks \\
\hline Brain size $(\mathrm{cm} 3)$ & 1,364 & 1,347 & 1,267 \\
\hline Cortical neurons (billions) & 13,767 & 13,665 & 13,185 \\
\hline \multicolumn{4}{|l|}{ Intelligence } \\
\hline IQ scores & 105 & 100 & $70-85$ \\
\hline Decision times & Faster & Intermediate & Slower \\
\hline Cultural achievements & Higher & Higher & Lower \\
\hline \multicolumn{4}{|l|}{ Maturation rate } \\
\hline Gestation time & Longer & Longer & Shorter \\
\hline Skeletal development & Later & Intermediate & Earlier \\
\hline Motor development & Later & Intermediate & Earlier \\
\hline Dental development & Later & Intermediate & Earlier \\
\hline Age of first intercourse & Later & Intermediate & Earlier \\
\hline Age of first pregnancy & Later & Intermediate & Earlier \\
\hline Life-span & Longest & Intermediate & Shortest \\
\hline \multicolumn{4}{|l|}{ Personality } \\
\hline Activity level & Lower & Intermediate & Higher \\
\hline Aggressiveness & Lower & Intermediate & Higher \\
\hline Cautiousness & Higher & Intermediate & Lower \\
\hline Dominance & Lower & Intermediate & Higher \\
\hline Impulsivity & Lower & Intermediate & Higher \\
\hline Self-esteem & Lower & Intermediate & Higher \\
\hline Sociability & Lower & Intermediate & Higher \\
\hline \multicolumn{4}{|l|}{ Social Organization } \\
\hline Marital stability & Higher & Intermediate & Lower \\
\hline Law abidingness & Higher & Intermediate & Lower \\
\hline Mental health & Higher & Intermediate & Lower \\
\hline \multicolumn{4}{|l|}{ Reproductive Effort } \\
\hline Two-egg twinning (per 1000 births) & 4 & 8 & 16 \\
\hline Hormone levels & Lower & Intermediate & Higher \\
\hline Size of genitalia & Smaller & Intermediate & Larger \\
\hline Secondary sex characteristics & Smaller & Intermediate & Higher \\
\hline Intercourse frequencies & Lower & Intermediate & Higher \\
\hline Permissive attitudes & Lower & Intermediate & Higher \\
\hline Sexually transmitted diseases & Lower & Intermediate & Higher \\
\hline
\end{tabular}

Note: Adapted from Rushton [23]. 
Some of Nisbett's errors that are of commission might be due to seeing the data differently, as when he exaggerated the magnitude of the Black IQ score gains. He claimed they amounted to 4.5 out of 15 points $(30 \%)$ even after the inclusion of the small and negative gains that Rushton and Jensen [25] argued Dickens and Flynn [24] had left out, rather than the 2.1 points $(14 \%)$ calculated by Rushton and Jensen (Section 2). Similarly, on the NAEP achievement tests, he claimed a Black gain of $35 \%$ instead of the $20 \%$ reported by Gottfredson [28] - perhaps due to the fact that he and Gottfredson used different measures and Nisbett excluded the NAEP Science test that Gottfredson included, which showed a full 1 SD Black-White difference.

Other errors were of omission. For example, when Nisbett discussed culture-loaded versus $g$-loaded tests, he failed to mention Flynn's [18] apparent change of heart over the importance of the $g$ factor for Black-White differences (Section 3). Flynn stated that, "the black gains are like hearing aids. They do cut the cognitive gap but they are not eliminating the root causes.... if the root causes are somehow eliminated, we can be confident that the IQ gap and the $g$ gap will both disappear" (p. 85).

Perhaps Nisbett overlooked (or had forgotten) the large data sets we marshaled in a paper [8] on which he was a commentator [190], against the stereotype threat hypothesis, Ogbu's caste theory, or the other "X factors" he described, for he never mentioned them (Section 4). Unfortunately Nisbett's highly selective method appeared again and again. For example, in his discussion of reaction time tasks (in Section 5), he minimized the magnitude of the inter-task correlations (.20 instead of .60); in his discussion of the adoption and heritability studies of young children showing how malleable IQ can be, he neglected to inform his readers that these effects are known to dissipate by late adolescence (Section 6); in his suggestion that heritability is lower in Blacks due to oppressive social conditions, he neglected to cite the studies showing equal heritabilities (Section 7); and in his citation of Turkheimer's [86, 90] finding of lower heritabilities for the poorest social class, he omitted to mention that other behavior genetic studies did not replicate them (also Section 7).

Most seriously, one has to consider Nisbett's exclusion of so much of the data on East Asians, which provided evidence of a three-step racial gradient in IQ and brain size from Blacks to Whites to East Asians. A focus on three racial groups taken together obviously provides researchers with increased opportunity to test their hypotheses about group differences. In many cases, diacritical comparisons of East Asians and Whites versus Blacks and Whites, allow the roles of genetics and environment to be unconfounded as, for example, in the case of malnutrition and later adopted children.

Since Nisbett [191] had previously written a book about East Asians, and now devoted a whole chapter to them, he was undoubtedly aware of the importance of such crosscultural comparisons. Yet Nisbett first omitted to discuss Lynn and Vanhanen's [14] most recent IQ data on East Asians (from 2006) on the grounds that Flynn [192] had much earlier (1991) claimed that Lynn had used small, unrepresentative samples and outmoded norms (Section 1). Then he described the work done on reaction time measures, but failed to acknowledge that East Asians have faster decision times, slower movement times, and more stable variability than Whites, who showed the exact same pattern in regard to Blacks (Section 5). He then neglected to mention that the East Asian advantage on reaction time measures occurs on the $g$ factor extracted from both reaction time measures and IQ tests (also Section 5). Then, while judging inadequate a major trans-racial adoption study finding Black children continued to have a low mean IQ despite being raised by upper-middle class White parents, he failed to mention three independent studies of East Asian children adopted by White parents who grew to excel in both IQ and educational achievement, despite being malnourished at birth (Section 11).

In regard to the East Asian brain size advantage, Nisbett cited a data set from NASA in order to point to a single African sample that couldn't be included in analyses because it had no variance while completely ignoring an analysis of the same NASA data set documenting the East Asian brain size advantage (Section 9). He also failed to mention any of the other brain size studies of East Asians, which found the East Asian advantage at birth, 1 year, 7 years, and adulthood. Reporting these data would have contradicted his hypothesis that the reason why Blacks "sometimes" averaged a smaller brain size than Whites is because of their lower birth weight and poorer subsequent nutrition. In fact, it was the East Asian samples, from birth to age 7 , who were the smallest in stature and lightest in weight, while the Black samples were the tallest in stature and heaviest in weight (Section 9).

As we continued to read, we came across many other instances of avoidance of unwelcome evidence. For example, Nisbett selected the one and only study failing to find an absence of a within-family relationship between brain size and IQ, while neglecting to mention four other studies that found the relationship (Section 9). Similarly, in regard to racial admixture studies, he omitted all mention of the "Colored" population of South Africa having IQ scores of 85, intermediate to the parental populations of Africans and Whites, while relying instead on several outdated and heavily recycled studies, which had been responded to 35 years ago (Section 12).

We found similar examples of selective bias in Nisbett's discussion of regression to the mean. Here, he provided an alternative account of how cultural factors might lead the children of very high IQ Black parents to regress further than the children of similarly high IQ White parents. But he neglected to mention the data regarding regression at the other end of the distribution (that is, regression up from very low IQ parents), which contradicted his argument (Section 13). Nisbett also neglected to mention that studies of siblings demonstrate precise fits to genetic predictions, as well as the evidence that Black siblings regress to a lower mean than do White siblings.

We found Nisbett's errors of omission and of commission so major, so many, and so misleading, that they forced us to write a particularly long and negative review. Sadly, they soured us to the many points we found admirable and informative on first reading. These include his acknowledgement of the solid consensus among expert opinion: the existence of intelligence as a meaningful human trait; the 
heritability of IQ within the White population and its relation to social class; many of the population group differences in achievement now found internationally; the relation between IQ test scores and MRI-brain size relations; and the neurophysiological reaction time correlates of intelligence (measured in milliseconds).

We found it hard to disagree with Nisbett's common sense view that to reform education it is necessary to carry out experiments in classrooms in order to identify the best methods of instruction. Nor could we disagree with Nisbett's advice that to maintain IQ scores it is best to exercise, avoid smoking or abusing alcohol and drugs, do homework, read books, and seek out studious peers. We also found much that was useful in his cost-benefit survey of what has been done and what can be done to increase test scores and school performance. Sadly, the answer, as one of us (ARJ) pointed out in 1969, is still "not much" [20].

Contrary to many hopes and some claims, the narrowing of the gap in social conditions between Blacks and Whites has not led to any change in the magnitude of the BlackWhite IQ difference in over 100 years. Massive society-wide interventions such as ending segregation, the subsequent nationwide program of school busing to achieve racial balance, and the Head Start programs have failed to reduce this difference. Head Start programs did produce modest gains in school retention and graduation rates among Whites-but not Blacks [193]. Other large scale, often well-publicized, countywide amelioration projects have not reduced the Black-White achievement gap (despite desirably low student-teacher ratios and computers in every classroom) [8]. Adjusting for socioeconomic status, which itself contains much heritable variance, only reduces the Black-White IQ difference by about one-third [8].

There is no value in denying reality. While improving opportunities and removing arbitrary barriers is a worthy ethical goal, we must realize that equal opportunity will result in equitable, though unequal outcomes. Expanding on the application of his "default hypothesis" that group differences are based on aggregated individual differences, themselves based on both genetic and environmental contributions, Jensen [74] proposed "two laws of individual differences"-(1) individual differences in learning and performance increase as task complexity increases, and (2) individual differences in performance increase with practice and experience (unless there is a low ceiling on proficiency). We must recognize that the more environmental barriers are ameliorated and everybody's intellectual performance is improved, the greater will be the relative influence of genetic factors (because the environmental variance is being removed). This means that equal opportunity will result in unequal outcomes, within-families, between-families, and between population groups. The fact that we have learned to live with the first, and to a lesser degree the second, offers some hope we can learn to do so for the third.

\section{REFERENCE}

[1] Degler CN. In search of human nature. New York: Oxford University Press 1991.

[2] Loehlin JC, Lindzey G, Spuhler JN. Race differences in intelligence. San Francisco, CA: W. H. Freeman 1975.

[3] Galton F. Hereditary genius. London: Macmillan 1869.
[4] Nott JC, Glidden GR. Types of mankind. Philadelphia, PA: Lippincott 1854 .

[5] Nisbett RE. Intelligence and how to get it: why schools and cultures count. New York: Norton 2009.

[6] Shuey AM. The testing of Negro intelligence 2nd ed. New York: Social Science Press 1966.

[7] Herrnstein RJ, Murray C. The bell curve. New York, NY: Free Press 1994.

[8] Rushton JP, Jensen AR. Thirty years of research on group differences in cognitive ability. Psychol, Public Policy, Law 2005; 11: 235-94.

[9] Roth PL, Bevier CA, Bobko P, Switzer III FS, Tyler P. Ethnic group differences in cognitive ability in employment and educational settings: a meta-analysis. Pers Psychol 2001; 54: 297330.

[10] Vernon PE. The abilities and achievements of Orientals in North America. New York: Academic Press 1982.

[11] Lynn R. Race differences in intelligence: an evolutionary analysis. Augusta, GA: Washington Summit Books 2006.

[12] Lynn R. The global bell curve. Augusta, GA: Washington Summit Books 2008.

[13] Lynn R, Vanhanen T. IQ and the wealth of nations. Westport, CT: Praeger 2002.

[14] Lynn R, Vanhanen T. IQ and global inequality. Augusta, GA: Washington Summit Books 2006.

[15] Cavalli-Sforza LL, Menozzi P, Piazza A. The history and geography of human genes. Princeton, NJ: Princeton University Press 1994.

[16] Flynn JR. Massive IQ gains in 14 nations: what IQ tests really measure. Psychol Bull 1987; 101: 171-191.

[17] Flynn JR. What is intelligence? beyond the flynn effect. New York: Cambridge University Press 2007.

[18] Flynn JR. Where have all the liberals gone? Race, class, and ideals in America. New York: Cambridge University Press 2008.

[19] Mingroni MA. Resolving the IQ paradox: heterosis as a cause of the Flynn effect and other trends. Psychol Rev 2007; 114: 80629.

[20] Jensen AR. How much can we boost IQ and scholastic achievement? Harvard Educ Rev 1969; 39: 1-123.

[21] Jensen AR. Educability and group differences. London: Methuen 1973.

[22] Jensen AR. The g factor. Westport, CT: Praeger 1998.

[23] Rushton JP. Race, evolution, and behavior: a life history perspective. New Brunswick, NJ: Transaction 1995.

[24] Dickens WT, Flynn JR. Black Americans reduce the racial IQ gap: Evidence from standardization samples. Psychol Sci 2006; 17: 91320.

[25] Rushton JP, Jensen AR. The totality of available evidence shows race-IQ gap still remains. Psychol Sci 2006; 17: 921-2.

[26] Murray C. Changes over time in the black-white difference on mental tests: evidence from the children of the 1979 Cohort of the National Longitudinal Survey of Youth. Intelligence 2006; 34: 52740.

[27] Murray C. The magnitude and components of change in the blackwhite IQ difference from 1920 to 1991: a birth cohort analysis of the Woodcock-Johnson standardizations. Intelligence 2007; 35: 305-18.

[28] Gottfredson LS. Implications of cognitive differences for schooling within diverse societies In: Frisby CL, Reynolds CR, Eds. Comprehensive Handbook of Multicultural School Psychology. New York: Wiley 2005; pp. 517-54.

[29] Gottfredson LS. What if the hereditarian hypothesis is true? Psychol Public Policy Law 2005; 11:311-9.

[30] Jensen AR. Cumulative deficit in IQ of blacks in the rural south. Dev Psychol 1977; 13: 184-91.

[31] Hills JR, Stanley JC. Easier test improves prediction of black students' college grades. J Negro Educ 1970; 39: 320-4.

[32] Flynn JR. IQ gains, WISC subtests and fluid g: g theory and the relevance of Spearman's hypothesis to race. In: Bock GR, Goode JA, Webb K, Eds. The nature of intelligence: The Novartis Foundation symposium. New York: Wiley 2000; pp. 202-27.

[33] Nichols PL. The effects of heredity and environment on intelligence test performance in 4- and 7- year-old white and Negro sibling pairs. Unpublished doctoral dissertation. University of Minnesota, Minneapolis 1972. 
[34] Rushton JP. Japanese inbreeding depression scores: Predictors of cognitive differences between Blacks and Whites. Intelligence 1989; 13: 43-51

[35] Schull WJ, Neel JV. The effects of inbreeding on Japanese children. New York: Harper \& Row 1965.

[36] Peoples CE, Fagan III JF, Drotar D. The influence of race on 3year-old children's performance on the Stanford-Binet: Fourth edition. Intelligence 1995; 21: 69-82.

[37] Nagoshi CT, Johnson RC, DeFries JC, Wilson JR, Vandenberg SG. Group differences and first principal-component loadings in the Hawaii Family Study of Cognition: a test of the generality of “Spearman's hypothesis." Pers Individ Dif 1984; 5: 751-3.

[38] Rushton JP, Jensen AR. African-White IQ differences from Zimbabwe on the Wechsler Intelligence Scale for Children-Revised are mainly on the $\mathrm{g}$ factor. Pers Individ Dif 2003; 34: 177-83.

[39] Zindi F. Differences in performance. Psychologist 1994; 7: 54952.

[40] Rushton JP, Skuy M, Fridjhon P. Performance on Raven's Advanced Progressive Matrices by African, Indian, and White engineering students in South Africa. Intelligence 2003; 31: 12337.

[41] Rushton JP, Skuy M, Bons TA. Construct validity of Raven's Advanced Progressive Matrices for African and non-African engineering students in South Africa. Int J Sel Assess 2004; 12: 220-9.

[42] Flynn JR. Evidence against Rushton: The genetic loading of WISC$\mathrm{R}$ subtests and the causes of between-group IQ differences. Pers Individ Dif 1999; 26: 373-9.

[43] Rushton JP. Secular gains in IQ not related to the $\mathrm{g}$ factor and inbreeding depression -- unlike Black-White differences: a reply to Flynn. Pers Individ Dif 1999; 26: 381-9.

[44] Fisher RA. Statistical methods for research workers, 14th ed. New York: Hafner Press 1970.

[45] Flynn JR. Reply to Rushton: a gang of gs overpower factor analysis. Pers Individ Dif 1999; 26: 391-3.

[46] Lynn R, Cooper C. A secular decline in the strength of Spearman's $\mathrm{g}$ in France. Learn Individ Dif 1993; 5: 43-8.

[47] Lynn R, Cooper C. A secular decline in the strength of Spearman's $\mathrm{g}$ in Japan. Curr Psychol 1994; 13: 3-9.

[48] Colom R, Juan-Espinosa M, Garcia LF. The secular increase in test scores is a "Jensen effect." Pers Individ Dif 2001; 30: 553-9.

[49] Must O, Must A, Raudik V. The secular rise in IQs: in Estonia, the Flynn effect is not a Jensen effect. Intelligence 2003; 31: 46171.

[50] te Nijenhuis J, van der Flier H. The secular rise in IQs in the Netherlands: is the Flynn effect on g? Pers Individ Dif 2007; 43: 125965.

[51] te Nijenhuis J, van der Flier H. Is the Flynn Effect on g? a metaanalysis. Manuscript submitted for publication. University of Amsterdam 2009.

[52] Wicherts JM, Dolan CV, Hessen DJ, Oosterveld P, van Baal CM, Boomsma DI, Span MM. Are intelligence tests measurement invariant over time? Investigating the nature of the Flynn effect. Intelligence 2004; 32: 509-37.

[53] Dolan CV. Investigating Spearman's hypothesis by means of multigroup confirmatory factor analysis. Multivariate Behav Res 2000; 35: $21-50$.

[54] Dolan CV, Hamaker EL. Investigating Black-White differences in psychometric Q: Multi-group confirmatory factor analyses of the WISC-R and K-ABC and a critique of the method of correlated vectors. In: Columbus F, Ed. Advances in Psychology Research. Huntington, NY: Nova Science Publishers 2001; vol. 6 pp. 31-59.

[55] Spearman C. "General intelligence," objectively determined and measured. Am J Psychol 1904; 15: 201-92.

[56] Jensen AR. Bias in mental testing. New York: Free Press 1980.

[57] Osborne RT. The Spearman-Jensen hypothesis. Behav Brain Sci 1980; 3: 351.

[58] Rushton JP. The "Jensen Effect" and the "Spearman-Jensen Hypothesis" of Black-White IQ differences. Intelligence 1998; 26: 217-25.

[59] Dolan CV, Roorda W, Wicherts JM. Two failures of Spearman's hypothesis: The GATB in Holland and the JAT in South Africa. Intelligence 2004; 32: 155-73.

[60] Ashton M, Lee K. Problems with the method of correlated vectors. Intelligence 2005; 33: 431-44.

[61] Bartholomew DJ. Measuring intelligence: facts and fallacies. Cambridge: Cambridge University Press 2004.
[62] Rushton JP, Cvorovic J, Bons TA. General mental ability in South Asians: data from three Roma (Gypsy) Communities in Serbia. Intelligence 2007; 35: 1-12.

[63] Rushton JP, Bons TA, Vernon PA, Cvorovic J. Genetic and environmental contributions to population group differences on the $\mathrm{Ra}$ ven's Progressive Matrices estimated from twins reared together and apart. Proc R Soc Lond B Biol Sci 2007; 274: 1773-7.

[64] Wicherts JM, Johnson W. Group differences in the heritability of items and test scores. Proc R Soc Lond B Biol Sci 2009; 276: 267583 .

[65] Steele CM, Aronson J. Stereotype threat and the intellectual identity test performance of African Americans. J Pers Soc Psychol 1995; 69: 797-811.

[66] Ogbu JU. Black American students in an affluent suburb: a study of academic disengagement. Mahwah, NJ: Erlbaum 2003.

[67] Rowe DC. Under the skin: On the impartial treatment of genetic and environmental hypotheses of racial differences. Am Psychol 2005; 60: 60-70

[68] Rowe DC, Vazsonyi AT, Flannery DJ. No more than skin deep: ethnic and racial similarity in developmental process. Psychol Rev 1994; 101: 396-413.

[69] Rowe DC, Vazsonyi AT, Flannery DJ. Ethnic and racial similarity in developmental process: a study of academic achievement. Psychol Sci 1995; 6: 33-8.

[70] Ree MJ, Carretta TR. Group differences in aptitude factor structure on the ASVAB. Educ Psychol Meas 1995; 55: 268-77.

[71] Carretta TR, Ree MJ. Near identity of cognitive structure in sex and ethnic groups. Pers Indivi Dif 1995; 19: 149-55.

[72] Deary IJ. Looking down on human intelligence: from psychometrics to the brain. Oxford, UK: Oxford University Press 2000.

[73] Jensen AR. Individual differences in the Hick paradigm. In Vernon PA, Ed. Speed of information processing and intelligence. Norwood, NJ: Ablex 1987; pp. 101-75.

[74] Jensen AR. Clocking the mind: Mental chronometry and individual differences. Oxford: Elsevier 2006.

[75] Jensen AR. Spearman's hypothesis tested with chronometric information processing tasks. Intelligence 1993; 17: 47-77.

[76] Jensen AR, Whang PA. Speed of accessing arithmetic facts in longterm memory: a comparison of Chinese-American and AngloAmerican children. Contemp Educ Psychol 1994; 19: 1-12.

[77] Devlin B, Daniels M, Roeder K. The heritability of IQ. Nature 1997; 388: 468-71.

[78] Capron C, Duyme M. Assessment of the effects of socio-economic status on IQ in a full cross-fostering study. Nature 1989; 340: 5524.

[79] Duyme M, Dumaret A, Tomkiewicz S. How can we boost IQs of "dull" children? A large adoption study. Proc Natl Acad Sci USA 1999; 96: 8790-4.

[80] van IJzendoorn MH, Juffer F, Poelhuis CWK. Adoption and cognitive development: A meta-analytic comparison of adopted and nonadopted children's IQ and school performance. Psychol Bull 2005; 131: 301-16.

[81] Locurto C. The malleability of IQ as judged from adoption studies. Intelligence 1990; 14: 275-92.

[82] Plomin R, DeFries JC, McClearn GE, McGuffin P. Behavioral genetics, 5th ed. New York: Worth 2008.

[83] McGue M, Bouchard TJ Jr, Iacono WG, Lykken DT. Behavioral genetics of cognitive ability: A life-span perspective. In: Plomin R, McClearn GE, Eds. Nature, nurture, and psychology. Washington, DC: American Psychological Association 1993; pp. 59-76.

[84] Bouchard TJ. Jr. Genetic influence on human intelligence (Spearman's g): How much? Ann Hum Biol 2009; 36: 527-44.

[85] Jensen AR. Adoption data and two g-related hypotheses. Intelligence 1997; 25: 1-6.

[86] Turkheimer E, Haley A, Waldron M, D’Onofrio B, Gottesman II. Socioeconomic status modifies heritability of IQ in young children. Psychol Sci 2003; 14: 623-8.

[87] Dickens WT, Flynn JR. Heritability estimates versus large environmental effects: the IQ paradox resolved. Psychol Rev 2001; 108: 346-69.

[88] Bushan A, Hur Y-M. Twin registries: An ongoing success story. Twin Research and Hum Genet 2005; 9: 705-1037. (Special Issue).

[89] Osborne RT. Twins: black and white. Athens, GA: Foundation for Human Understanding 1980. 
[90] Harden KP, Turkheimer E, Loehlin JC. Genotype by environment interaction in adolescents' cognitive aptitude. Behav Genet 2006; 37: 273-83.

[91] Asbury K, Wachs TD, Plomin R. Environmental moderators of genetic influence on verbal and nonverbal abilities in early childhood. Intelligence 2005; 33: 643-61.

[92] Nagoshi CT, Johnson RC. Socioeconomic status does not moderate the familiality of cognitive abilities in the Hawaii Family Study of Cognition. J Biosoc Sci 2005; 37: 773-81.

[93] van der Sluis S, Willemsen G, de Geus EJC, Boomsma DI, Posthuma D. Gene-environment interaction in adults' IQ scores: measures of past and present environment. Behav Genet 2008; 38: 348-60.

[94] Rowe DC, Cleveland HH. Academic achievement in Blacks and Whites: Are the developmental processes similar? Intelligence 1996; 23: 205-28.

[95] Loehlin JC. The IQ paradox: Resolved? Still an open question. Psychol Rev 2002; 109: 754-58.

[96] Rowe DC, Rodgers JL. Expanding variance and the case of historical changes in IQ means: a critique of Dickens and Flynn. Psychol Rev 2002; 109: 759-63.

[97] Wicherts JM, Dolan CV, Carlson JS, van der Maas HLJ. Raven's test performance of Africans: average performance, psychometric properties, and the Flynn Effect. Unpublished manuscript, University of Amsterdam. Under review 2009.

[98] Wicherts JM, Dolan CV, van der Maas HLJ. A systematic literature review of the average IQ of sub-Saharan Africans. Intelligence 2010; 38: 1-20.

[99] Skuy M, Gewer A, Osrin Y, Khunou D, Fridjhon P, Rushton JP. Effects of mediated learning experience on Raven's Matrices scores of African and non-African university students in South Africa. Intelligence 2002; 30: 221-32.

[100] Daley TC, Whaley SE, Sigman MD, Espinosa MP, Neumann C. IQ on the rise: The Flynn effect in rural Kenyan children. Psychol Sci 2003; $14: 215-9$.

[101] Lynn, R. The average IQ of sub-Saharan Africans assessed by the Progressive Matrices: Some comments on Wicherts, Dolan, Carlson, \& van der Maas. Unpublished manuscript. University of Ulster: United Kingdom 2009

[102] Lynn R, Meisenberg G. IQ in sub-Saharan Africa assessed from school assessments in math, science, and reading: some comments on Wicherts, Dolan, \& van der Maas. Intelligence 2010; 38: 21-29.

[103] Glewwe P, Jacoby H. Estimating the determinants of cognitive achievement in low-income countries. Washington, DC: World Bank 1992.

[104] Owen K. The suitability of Raven's Standard Progressive Matrices for various groups in South Africa. Pers Individ Dif 19921; 13: 14959.

[105] Sternberg RJ, Nokes C, Geissler PW, Prince R, Okatcha F, Bundy DA, Grigorenko EL. The relationship between academic and practical intelligence: a case study in Kenya. Intelligence 2001; 29: 401-18.

[106] Sternberg RJ, Grigorenko EL, Ngrosho D, Tantufuye E, Mbise A, Nokes C, Jukes M, Bundy DA. Assessing intellectual potential in rural Tanzanian school children. Intelligence 2002; 30: 141-62.

[107] Rushton JP. Testing the genetic hypothesis of group mean IQ differences in South Africa: racial admixture and cross-situational consistency. Pers Individ Dif 2008; 44: 768-76.

[108] Grieve KW, Viljoen S. An exploratory study of the use of the Austin Maze in South Africa. S Afr J Psychol 2000; 30: 14-8.

[109] te Nijenhuis J, van Vianen AEM, van der Flie H. Score gains on gloaded tests: No g. Intelligence 2007; 35: 283-300.

[110] Kendall IM, Verster MA, von Mollendorf JW. Test performance of blacks in Southern Africa. In: Irvine SH, Berry JW, Eds. Human abilities in cultural context. Cambridge, UK: Cambridge University Press 1988 pp. 299-39.

[111] National Aeronautics and Space Administration. Anthropometric source book: Anthropometry for Designers (NASA Reference Publication 1024). 1987; vol. 1.

[112] Ho KC, Roessmann U, Straumfjord JV, Monroe G. Analysis of brain weight: I \& II. Arch Pathol Lab Med 1980; 104: 635-45.

[113] Ho KC, Roessmann U, Hause L, Monroe G. Newborn brain weight in relation to maturity, sex, and race. Ann Neurol 1981; 10: 2436.

[114] Schoenemann PT, Budinger TF, Sarich VM, Wang W. Brain size does not predict general cognitive ability within families. Proc Natl Acad Sci 2000; 97: 4932-7.
[115] Guevara-Aguire J, Rosenbloom AL, Vaccarelo MA, Fielder PJ, de la Vega A, Diamond F. B. Growth hormone receptor deficiency (Laron syndrome): clinical and genetic characteristics. Acta Paediatrica Scandinavia 1991; 377(Suppl): 96-103.

[116] Rushton JP, Ankney CD. Whole-brain size and general mental ability: a review. Int J Neurosci 2009; 119: 691-731.

[117] Posthuma D, De Geus EJC, Baare WFC, Pol HEH, Kahn RS, Boomsma DI. The association between brain volume and intelligence is of genetic origin. Nat Neurosci 2002; 5: 83-4.

[118] Chiang M-C, Barysheva M, Shattuck DW, Lee AD, Madsen SK, Avedissian C, Klunder AD, Toga AW, McMahon KL, de Zubicaray GI, Wright MJ, Srivastava A, Balov N, Thompson PM. Genetics of brain fiber architecture and intellectual performance. J Neurosci 2009; 29: 2212-24.

[119] Bergvall N, Iliadou A, Tuvemo T, Cnattingius S. Birth characteristics and risk of low intellectual performance in early adulthood: are the associations confounded by socioeconomic factors in adolescence or familial effects? Pediatrics 2006; 117: 714-21.

[120] Gignac G, Vernon PA,Wickett JC. Factors influencing the relationship between brain size and intelligence. In: Nyborg H, Ed. The scientific study of general intelligence: Tribute to Arthur R. Jensen. London: Elsevier 2003; pp. 93-106.

[121] Jensen AR. Psychometric g related to differences in head size. Pers Individ Dif 1994; 17: 597-606.

[122] Jensen AR, Johnson FW. Race and sex differences in head size and IQ. Intelligence 1994; 18: 309-33.

[123] Harvey I, Persaud R, Ron MA, Baker G, Murray RM. Volumetric MRI measurements in bipolars compared with schizophrenics and healthy controls. Psychol Med 1994; 24: 689-99.

[124] Jones PB, Harvey I, Lewis SW, Toone BK, Van Os J, Williams M, Murray R. M. Cerebral ventricle dimensions as risk factors for schizophrenia and affective psychosis: an epidemiological approach to analysis. Psychol Med 1994; 24: 995-1011.

[125] Broca P. Sur les crânes de la caverne de l'Homme Mort (Loere). Revue d'Anthropologie 1873; 2: 1-53.

[126] Bean RB. Some racial peculiarities of the Negro brain. Am J Anat 1906; 5: 353-432.

[127] Mall FP. On several anatomical characters of the human brain, said to vary according to race and sex, with special reference to the weight of the frontal lobe. Am J Anat 1909; 9: 1-32.

[128] Pearl R. (1934). The weight of the Negro brain. Science 1934; 80: 431-4.

[129] Vint FW. The brain of the Kenya native. J Anat 1934; 48: 216-23.

[130] Holloway R. Personal communications; 2002.

[131] Morton SG. Observations on the size of the brain in various races and families of man. Proc Acad Nat Sci Philadelphia 1849; 4: 2214.

[132] Gordon HL. Amentia in the East African. Eugen Rev 1934; 25 : 223-35.

[133] Simmons K. Cranial capacities by both plastic and water techniques with cranial linear measurements of the Reserve Collection: White and Negro. Hum Biol 1942; 14: 473-98.

[134] Todd TW. Cranial capacity and linear dimensions, in White and Negro. Am J Phys Anthropol 1923; 6: 97-194.

[135] Beals KL, Smith CL, Dodd SM. Brain size, cranial morphology, climate, and time machines. Curr Anthropol 1984; 25: 301-30.

[136] Rushton JP. Mongoloid-Caucasoid differences in brain size from military samples. Intelligence 1991; 15: 351-9.

[137] Rushton JP. Cranial capacity related to sex, rank, and race in a stratified random sample of 6,325 U.S. military personnel. Intelligence 1992; 16: 401-13.

[138] Schultz AH. Comparison of White and Negro fetuses. In: Davenport CB, Osborn HF, Wissler C, Laughlin HH, Eds. Scientific Papers of the Second International Congress of Eugenics: Vol. 2, Eugenics in Race and State (Plates 11 and 12). Baltimore, MD: Williams \& Wilkins 1923

[139] Broman SH, Nichols PL, Shaughnessy P, Kennedy W. Retardation in young children. Hillsdale, NJ: Erlbaum 1987.

[140] Rushton JP. Cranial size and IQ in Asian Americans from birth to age seven. Intelligence 1997; 25: 7-20.

[141] Kranzler JH, Rosenbloom AL, Martinez V, Guevara-Aguire J. Normal intelligence with severe insulin-like growth factor I deficiency due to growth hormone receptor deficiency: A controlled study in a genetically homogeneous population. J Clin Endocrinol Metab 1998; 83: 1953-8. 
[142] Ankney CD. Sex differences in relative brain size: The mismeasure of woman, too? Intelligence 1992; 16: 329-36.

[143] Joiner TE. Head size as an explanation of the race-measured IQ relation: negative evidence from child and adolescent samples. Sci Rev Ment Health Prac 2004; 3: 23-32.

[144] Kimura D. Sex and cognition. Cambridge, MA: MIT Press 1999.

[145] Voyer D, Voyer S, Bryden MP. Magnitude of sex differences in spatial abilities: A meta-analysis and consideration of critical variables. Psychol Bull 1995; 117: 250-70.

[146] Lynn R. Sex differences in intelligence and brain size: a paradox resolved. Pers Individ Dif 1994; 17: 257-71.

[147] Lynn R. Sex differences in intelligence and brain size: a developmental theory. Intelligence 1999; 27: 1-12.

[148] Broca P. Sur le volume et la forme du cerveau suivant les individus et suivant les races. Bulletin Société d'Anthropologie Paris 1861; 2: 139-207, 301-321, 441-446.

[149] Lynn R, Irwing P. Sex differences on the Progressive Matrices: a meta-analysis. Intelligence 2004; 32: 481-98.

[150] Irwing P, Lynn R. Sex differences in means and variability on the Progressive Matrices in university students: a meta-analysis. Br J Psychol 2005; 96: 505-24.

[151] Irwing P, Lynn R. Is there a sex difference in IQ scores? Nature 2006; 442: 31-2.

[152] Jackson DN, Rushton JP. Males have greater g: sex differences in general mental ability from 100,00017 - to 18 -year-olds on the Scholastic Assessment Test. Intelligence 2006; 34: 479-86.

[153] Nyborg H. Sex-related differences in general intelligence g, brain size, and social status. Pers Individ Dif 2005; 39: 497-509.

[154] Rushton JP, Osborne RT. Genetic and environmental contributions to cranial capacity estimated in Black and White adolescents. Intelligence 1995; 20: 1-13.

[155] Paterson DG. Physique and intellect. New York: Century 1930.

[156] Scarr S, Weinberg RA. IQ test performance of black children adopted by white families. Am Psychol 1976; 31: 726-39.

[157] Weinberg RA, Scarr S, Waldman ID. The Minnesota Transracial Adoption Study: a follow-up of IQ test performance at adolescence. Intelligence 1992; 16: 117-35.

[158] Tizard B, Cooperman A, Tizard J. Environmental effects on language development: A study of young children in long-stay residential nurseries. Child Dev 1972; 43: 342-3.

[159] Moore EGJ. Family socialization and the IQ test performance of traditionally and transracially adopted black children. Dev Psychol 1986; 22: 317-26.

[160] Winick M, Meyer KK, Harris RC. Malnutrition and environmental enrichment by early adoption. Science 1975; 190: 1173-5.

[161] Clark EA, Hanisee J. Intellectual and adaptive performance of Asian children in adoptive American settings. Dev Psychol 1982; 18: 595-9.

[162] Frydman M, Lynn R. The intelligence of Korean children adopted in Belgium. Pers Individ Dif 1989; 10: 1323-6.

[163] Parra EJ, Kittles RA, Shriver MD. Implications of correlations between skin color of genetic ancestry for biomedical research. Nat Genet 2004; 36: S54-S60.

[164] Loehlin JC, Vandenberg SG, Osborne RT. Blood group genes and Negro-White differences. Behav Genet 1973; 3: 263-70.

[165] Scarr S, Pakstis AJ, Katz SH, Barker WB. Absence of a relationship between degree of White ancestry and intellectual skills within a Black population. Hum Genet 1977; 39: 69-86.

[166] Eyferth K. Leistungern verscheidener Gruppen von Besatzungskindern in Hamburg-Wechsler Intelligenztest für Kinder (HAWIK). Archiv für die gesamte Psychologie 1961; 113: 222-41.

[167] Witty PA, Jenkins MD. The educational achievement of a group of gifted Negro children. J Educ Psychol 1934; 25: 585-97.
[168] Witty PA, Jenkins MD. Inter-race testing and Negro intelligence. J Psychol 1936; 1: 188-91.

[169] Willerman L, Naylor AF, Myrianthopoulos NC. Intellectual development of children from interracial matings: performance in infancy and at 4 years. Behav Genet 1974; 4: 84-8.

[170] Lynn R. Skin color and intelligence in African Americans. Popul Environ 2002; 23: 365-75.

[171] Rowe DC. IQ, birth weight, and number of sexual partners in White, African American, and mixed race adolescents. Popul Environ 2002: 23: 513-24.

[172] Templer DI, Arikawa H. Temperature, skin color, per capita income, and IQ: an international perspective. Intelligence 2006; 34 121-39.

[173] Templer DI. Correlational and factor analytic support for Rushton's differential K life-history theory. Pers Individ Dif 2008; 45: 440-4.

[174] Templer DI. IQ and skin color: The Old World re-examined and the New World. Unpublished manuscript.

[175] Rushton JP, Templer DI. National differences in intelligence, crime, income, and skin color. Intelligence 2009; 37: 341-6.

[176] Jensen AR. Comments on correlation of IQ with skin color and geographical demographic variables. Intelligence 2006; 34: 128-31.

[177] Broman SH, Nichols PL, Kennedy W. Preschool IQ: prenatal and early developmental correlates. Hillsdale, NJ: Erlbaum 1975.

[178] McKeigue PM. Prospects for admixture mapping of complex traits. Am J Hum Genet 2005; 76: 1-7.

[179] Collins-Schramm HE, Kittles RA, Operario DJ, Weber JL, Criswell LA, Cooper RS, Seldin MF. Markers that discriminate between European and African ancestry show limited variation within Africa. Hum Genet 2002; 111: 566-9.

[180] Tang H. Quertermous T, Rodriguez B, et al. Genetic structure, selfidentified race/ethnicity, and confounding in case-control association studies. Am J Hum Gen 2005; 76: 268-75.

[181] Brown P, Maeda T. Post-Pleistocene diachronic change in East Asian facial skeletons: the size, shape and volume of the orbits. Anthropol Sci 2004: 112: 29-40.

[182] Ruff CB, Trinkaus E, Holliday TW. Body mass and encephalization in Pleistocene Homo. Nature 1997; 387: 173-6.

[183] Rosenberg KR, Zune L, Ruff CB. Body size, body proportions, and encephalization in a Middle Pleistocene archaic human from northern China. Proc Natl Acad Sci USA 2006; 103: 3552-6.

[184] Bailey DH, Geary DC. Hominid brain evolution: testing climatic, ecological, and social competition models. Hum Nat 2009: 20: 67-79.

[185] Russell DA. Exponential evolution: implications for intelligent extraterrestrial life. Adv Space Res 1983; 3: 95-103.

[186] Wilson EO. Sociobiology: the new synthesis. Cambridge, MA: Harvard University Press 1975.

[187] Rushton JP. Placing intelligence into an evolutionary framework or how $\mathrm{g}$ fits into the $\mathrm{r}-\mathrm{K}$ matrix of life history traits including longevity. Intelligence 2004; 32: 321-8.

[188] Bulmer MG. The biology of twinning in man. Oxford, UK: Clarendon Press 1970.

[189] Eiben OG. Growth and physical fitness of children and youth at the end of the XXth Century Preliminary report. Int J Anthropol 1998; 13: $129-36$.

[190] Nisbett RE. Heredity, environment, and race differences in IQ: a commentary on Rushton and Jensen. Psychol Public Policy Law 2005; 11: 302-10.

[191] Nisbett RE. The geography of thought: How Asians and Westerners think differently... and why. New York: Free Press 2003.

[192] Flynn JR. Asian Americans: Achievement beyond IQ. Hillsdale, NJ: Lawrence Erlbaum 1991.

[193] Currie J, Thomas D. Does head start make a difference? Am Econ Rev 1995; 85: 341-64. 